\title{
Hijacking Endocytosis and Autophagy in Extracellular Vesicle Communication: Where the Inside Meets the Outside
}

\author{
Giona Pedrioli ${ }^{1,2}$ and Paolo Paganetti, ${ }^{1,3 *}$ \\ ${ }^{1}$ Neurodegeneration Research Group, Laboratory for Biomedical Neurosciences, Neurocenter of Southern Switzerland, Ente \\ Ospedaliero Cantonale, Torricella-Taverne, Switzerland, ${ }^{2}$ Member of the International Ph.D. Program of the Biozentrum, \\ University of Basel, Basel, Switzerland, ${ }^{3}$ Faculty of Biomedical Sciences, Università della Svizzera Italiana, Lugano, \\ Switzerland
}

Extracellular vesicles, phospholipid bilayer-membrane vesicles of cellular origin, are emerging as nanocarriers of biological information between cells. Extracellular vesicles transport virtually all biologically active macromolecules (e.g., nucleotides, lipids, and proteins), thus eliciting phenotypic changes in recipient cells. However, we only partially understand the cellular mechanisms driving the encounter of a soluble ligand

OPEN ACCESS

Edited by:

Michel Salzet,

Lille University of Science and Technology, France

Reviewed by:

Dasa Cizkova,

University of Veterinary Medicine and Pharmacy in Košice, Slovakia

Adriana-Natalia Murgoci,

Karolinska Institutet (KI), Sweden

*Correspondence:

Paolo Paganetti

paolo.paganetti@eoc.ch

Specialty section:

This article was submitted to

Molecular Medicine,

a section of the journal

Frontiers in Cell and Developmental

Biology

Received: 16 August 2020

Accepted: 18 November 2020

Published: 07 January 2021

Citation:

Pedrioli G and Paganetti P (2021)

Hijacking Endocytosis and Autophagy

in Extracellular Vesicle

Communication: Where the Inside

Meets the Outside.

Front. Cell Dev. Biol. 8:595515.

doi: 10.3389/fcell.2020.595515 transported in the lumen of extracellular vesicles with its cytosolic receptor: a step required to evoke a biologically relevant response. In this context, we review herein current evidence supporting the role of two well-described cellular transport pathways: the endocytic pathway as the main entry route for extracellular vesicles and the autophagic pathway driving lysosomal degradation of cytosolic proteins. The interplay between these pathways may result in the target engagement between an extracellular vesicle cargo protein and its cytosolic target within the acidic compartments of the cell. This mechanism of cell-to-cell communication may well own possible implications in the pathogenesis of neurodegenerative disorders.

Keywords: aggregation, autophagy, cargo, cell-to-cell communication, endocytosis, extracellular vesicles, lysosome, neurodegeneration

\section{INTRODUCTION}

In multicellular organisms, cell-to-cell communication is a cardinal process that coordinates and synchronizes cellular activities, ensuring the correct function of tissues, organs, and ultimately the whole system. A broad variety of mechanisms has evolved to accomplish the transmission of information between neighboring or distant cells. Among these, lipid bilayer-membrane

Abbreviations: AD, Alzheimer disease; AEP, asparagine endopeptidase; ALS, amyotrophic lateral sclerosis; AP2, adaptor protein 2; ATG, autophagy-related; CAME, caveolin-mediated endocytosis; CLME, clathrin-mediated endocytosis; CMA, chaperone-mediated autophagy; CQ, chloroquine; EIPA, 5-(N-ethyl-N-isopropyl)amirolide; ESCRT, endosomal sorting complex required for transport; EVs, extracellular vesicles; FTLD, frontotemporal lobar degeneration; GBA, betaglucocerebrosidase; GSK3beta, glycogen synthase kinase 3 beta; HD, Huntington disease; HSC70, chaperone protein heat shock cognate 70; ILVs, intraluminal vesicles; LAMP2A, lysosomes-associated membrane protein type 2A; LC3, microtubuleassociated protein light chain 3; LIR, LC3-interacting region; MCL, mantle cell lymphoma; MHC-II, major histocompatibility complex II; mTOR, mammalian target of rapamycin; MVBs, multivesicular bodies; NFTs, neurofibrillary tangles; NHE, $\mathrm{Na}^{+} / \mathrm{H}^{+}$exchanger; TGFbeta1, transforming growth factor beta1; PD, Parkinson disease; PS, phosphatidylserine; RGD, ArgGly-Asp; RVG, rabies virus glycoprotein; TSE, transmissible spongiform encephalopathies; UBA, ubiquitin-associated; UPS, ubiquitin-proteasome system. 
nanovesicles released from cells act as vectors for short- and long-distance transport of biological messages. First described in the early 1980s as secreted exosomes derived from endosomes (Harding et al., 1983; Pan and Johnstone, 1983; Pan, 1985), their function was first proposed as an alternative degradative path through which cells expel dispensable intracellular molecules. The subsequent advances in isolation and characterization procedures depicted a more complex and heterogeneous population of secreted nanovesicles, for which the generic term "extracellular vesicles" (EVs) was coined (György et al., 2011). The first concept on their function was challenged by the observation that EVs secreted from B cells induce T-cell proliferation by activating major histocompatibility complex II (MHC-II) receptors carried on their surface (Raposo et al., 1996). More recently, a strong support for a relevant role of macromolecules transported by EVs in cell-to-cell communication is reflected by the demonstration that nucleic acids synthetized and encapsulated in EVs by the donor cells are active in recipient cells (Valadi et al., 2007). It is now established that EVs are required for multiple cellular processes in health and disease by contributing to immunomodulation, inflammation, cancer, and neurodegeneration (Mathieu et al., 2019). EVs even find applications as nanocarriers for therapeutic agents (Luan et al., 2017; Yang et al., 2018).

At least three main criteria can be defined for EVs to be accounted as functional vectors in cell-to-cell communication: secretion by the donor cell after selective macromolecule encapsulation, transport of the cargo to the target cell, and release of the transported messenger in the recipient cell for interaction with its effector. To date, the efforts in the field were primarily directed to understand the biogenesis and the mechanisms for the packaging of macromolecules in EVs (Raposo and Stoorvogel, 2013; Colombo et al., 2014; van Niel et al., 2018; Mathieu et al., 2019). EVs comprise small EVs (with a diameter of 30-150 nm) or large EVs (>150 nm) that mostly depend on their origin from endosomes or the cell surface, respectively (Colombo et al., 2014). Exosomes, a class of small EVs, are born as intraluminal vesicles (ILVs) by inward membrane budding during the maturation of multivesicular bodies (MVBs), a process that is regulated by the endosomal sorting complex required for transport (ESCRT) (Colombo et al., 2014; Cocucci and Meldolesi, 2015; Mathieu et al., 2019). The ESCRT-0 and ESCRT-I subcomplexes sort cargo molecules in membrane microdomains, and the ESCRTII and ESCRT-III subcomplexes drive membrane budding and fission. ILVs are also generated by ESCRT-independent mechanisms. This can occur by the hydrolysis of sphingomyelin to ceramide and the creation of membrane microdomains; further metabolism of ceramide to sphingosine 1-phosphate activates its receptor that sorts the cargo of ILVs (Colombo et al., 2014). In addition, members of the tetraspanin family, which are efficiently sorted to the endosomal pathway, appears involved in the sorting of EV cargo (van Niel et al., 2011). The fusion of MVBs at the cell surface results in exosome secretion. Large EVs, in particular microvesicles, predominantly originates from the outward budding of the plasma membrane (van Niel et al., 2011). Cargo packaging entails that macromolecules are first targeted to the respective production site. Then, with a process requiring molecular clustering and budding, they end up in EVs following membrane fission. The proteins involved in the biogenesis of EVs eventually become themselves cargo molecules and can be utilized as markers characterizing the origin of EVs (Colombo et al., 2014; Mathieu et al., 2019). On the other hand, although the delivery of cargo macromolecules to recipient cells is a critical step required for absolving the biological activities associated to EVs, the mechanisms involved in this process remain largely elusive. Macromolecules transported on the exterior of EV may directly interact with surface membrane receptors, as it may be the case for MHC-II receptors. For a luminal EV cargo, it is plausible to assume that the cytosol is the main site for intracellular target engagement. However, current evidence suggests that this is a possible but rather rare event (Ridder et al., 2014; Zomer et al., 2015; Sterzenbach et al., 2017). Inadequate detection sensitivity is a plausible technical limitation. In fact, circumstantial evidence indicates that a measurable biological effect is counterbalanced by the difficulty to detect a cargo molecule in the cytosol of the recipient cell (Zomer et al., 2015; Steenbeek et al., 2018; Pedrioli et al., 2020). Lack of sensitivity may result because recipient cells represent only a minor subpopulation able to decipher an EV message. In such a case, EVs specifically targeting a specialized cell pool present in an organ may reduce EV cargo release to a rare event that still holds a significant biological relevance (Ridder et al., 2014; Zomer et al., 2015). At the same time, a sporadic but continuous transport over years of pathological protein forms between cells may well contribute to a slow progression and propagation of disease as in the case of neurodegenerative disorders. That being said, an infrequent cytosolic EV cargo release does not exhaustively explain the large body of evidence, suggesting a cardinal role of EVs in cell-to-cell exchange of macromolecules. Nevertheless, given the broad heterogeneity of luminal cargos, there is the need to assess whether alternative intracellular locations may account for the release and the target engagement of biologically active EV cargo macromolecules.

\section{LOOKING FOR THE TARGET CELL}

The rising interest around EVs in recent years is linked to the increasing evidence of phenotypic changes in recipient cells apt to translate a message transported by these vesicles (Valadi et al., 2007; Ridder et al., 2014; Zomer et al., 2015; van Niel et al., 2018; Mathieu et al., 2019; Wang et al., 2019; O’Brien et al., 2020). The molecular process exploited by EVs to target recipient cells remains a matter of debate, possibly because different mechanisms may coexist. Human carcinoma cells were shown to non-selectively respond to EVs originating from different cell types (Horibe et al., 2018). The composition and modifications of external components may affect the overall charge of the EV surface, thus reducing the natural electrostatic repulsion of membranes (Williams et al., 2019). This process may become more relevant once EVs are internalized into the acid environment of endocytic organelles (Winchester, 2005). Besides a randomly determined event, a combination of EV and cell origin, EV subtype, and cell type 
and state may confer specificity to the recognition of EVs by the recipient cell, a mechanism defined as tropism of EVs (Kooijmans et al., 2016). EVs derived from B cells in mantle cell lymphoma (MCL) are readily and preferentially taken up by other MCL cells (Hazan-Halevy et al., 2015). In the nervous system, EVs secreted from oligodendrocytes have a specific tropism for microglia cells (Fitzner et al., 2011). In both cases, preferential EV internalization may occur because of active intake mechanisms characterizing these cell types. EV docking at the plasma membrane may be facilitated by cell membrane adhesion receptors recognizing macromolecules exposed on the surface of EVs. Tetraspanins, in particular CD9 and CD81, which are highly enriched in the lipid membranes of EVs, appear as possible candidates (Morelli et al., 2004). Additional proteins exposed on the EV surface participate in ligand-binding mechanisms. On dendritic cell-derived EVs, the beta-2 integrin family of proteins (CD18/CD11 a, b), the intercellular adhesion molecule-1 and -2 (ICAM-1/-2), and the serum milk fat globuleEGF factor 8 facilitate the interaction with recipient cells (Théry et al., 1999, 2001; Nolte-'T Hoen et al., 2009; Genschmer et al., 2019). Glycans as well may contribute to the EV and cell recognition process (Williams et al., 2018, 2019; Dusoswa et al., 2019). Glioblastoma-derived EVs are decorated with glycans recognized by sialic acid-binding immunoglobulin-like lectin receptors, an essential and specific step for their capture by dendritic cells (Dusoswa et al., 2019). To add complexity to the system, the heterogeneous size and composition of EVs may influence their recognition and uptake by recipient cells.

As all cell types secrete EVs, the extracellular milieu is rich in a large variety of EVs. A productive message possibly covering a distant radius of action requires that the target cell developed a precise instrument of docking and internalization of freely circulating EVs. The elucidation of the fate of EVs once docked on the cell surface is of critical importance in the context of disease. Understanding the molecular and cellular mechanisms involved in a pathogenic cell-to-cell communication mediated by EVs may offer new approaches for the development of specific treatments.

\section{“EATING AND DRINKING" EVs}

The variability in EV uptake routes may depend on the combination of multiple factors contributed by macromolecules present on the surface of both EVs and recipient cells (Mulcahy et al., 2014). Most experimental evidence suggests that endocytosis is the major uptake path (Koumangoye et al., 2011; Nanbo et al., 2013; Mulcahy et al., 2014; Heusermann et al., 2016; Nakase et al., 2016; Durak-Kozica et al., 2018; Yao et al., 2018). EVs are internalized by dendritic cells and fuse with membranes of the endocytic pathways releasing their content into the cytosol (Montecalvo et al., 2012). However, once taken up by recipient cells, EVs can also be either recycled and released in the extracellular space or targeted to lysosomes for degradation. For instance, upon internalization by interconnected neurons, fusion events between exogenous and endogenous EVs were found to potentially increase the radius of action of EVs and the consequent pathogenicity in the context of Alzheimer disease (AD) (Polanco et al., 2018). In contrast, microglia take up oligodendrocyte-derived EVs through a macropinocytotic mechanism on their route to lysosomes for degradation (Fitzner et al., 2011), consistent with their role in cleaning the extracellular space from cell debris.

The term "endocytosis" was coined by Christian de Duve in the 1960s to describe a cellular process in which the invagination of the limiting plasma membrane leads to the intracellular formation of vesicles encapsulating extracellular material (Fürthauer and Smythe, 2014). Various functions are now assigned to endocytosis, a key homeostatic mechanism that regulates major cellular processes such as provision of educts for biochemical synthesis of macromolecules, receptor down-regulation, intracellular signaling, antigen presentation (Miaczynska et al., 2004; Miaczynska and Stenmark, 2008; Ellinger and Pietschmann, 2016), or as the main route for EV internalization (Koumangoye et al., 2011; Nanbo et al., 2013; Mulcahy et al., 2014; Heusermann et al., 2016; Nakase et al., 2016; Durak-Kozica et al., 2018; Yao et al., 2018). Indeed, EV uptake through this route is rapid, with EVs identified inside cells within few minutes after their application to the culture medium (Feng et al., 2010). EV uptake requires an active process as shown by its absence in cells kept at $4^{\circ} \mathrm{C}$ or fixed with paraformaldehyde (Fitzner et al., 2011; Pan et al., 2012) and is therefore modulated by the same mechanisms regulating endocytosis (Joseph and Liu, 2020). Alternatively, it may occur by bulk flow, similarly, to the fluid phase-uptake marker dextran (Tian et al., 2014a; Nakase et al., 2016). Once internalized, EVs locate with various markers of the endocytic pathway. For instance, EVs derived from Epstein-Barr virus-infected B cells and tracked through a fluorescent lipophilic dye localize, at increasing time points, with RAB5, RAB7, and CD63-positive endocytic organelles of recipient epithelial cells (Nanbo et al., 2013). EVs are observed to enter human primary fibroblasts via filopodia and travel along the endocytic pathway and end their route, after scanning the endoplasmic reticulum, in lysosomes (Heusermann et al., 2016). Consistent with this, EVs appear to exploit the endocytic pathway to travel from the periphery, rich in early endosomes, toward the perinuclear area, rich in late endosomes and lysosomes, or they are sorted and recycled by secretion at the plasma membrane (Mercer et al., 2010; Durak-Kozica et al., 2018), as described for protein receptors (Gonda et al., 2019). Indeed, EVs (and viral particles) are found within lysosomes of recipient cells as soon as $1 \mathrm{~h}$ after application (Koumangoye et al., 2011; Zhou et al., 2011; Yao et al., 2018). This close proximity with the nucleus is hijacked for the delivery of viral genomic material to "the control center of the cell" and may hint to a possible shared delivery mechanism also used by EVs (Mercer et al., 2010). Endocytosis is a broad term that includes a range of internalization pathways that include cell eating ("phagocytosis") and cell drinking ("pinocytosis") processes, both involved in EV internalization (Feng et al., 2010; Tian et al., 2014a; Ellinger and Pietschmann, 2016; Holder et al., 2016; Chiba et al., 2018; Horibe et al., 2018; Ogese et al., 2019; Verweij et al., 2019; Figure 1).

\section{Phagocytosis}

Phagocytosis is the main internalization path shared by professional phagocytic cells, which embrace neutrophils, macrophages, and dendritic cells (Savina and Amigorena, 2007; Richards and Endres, 2014). Phagocytosis is tightly regulated, 


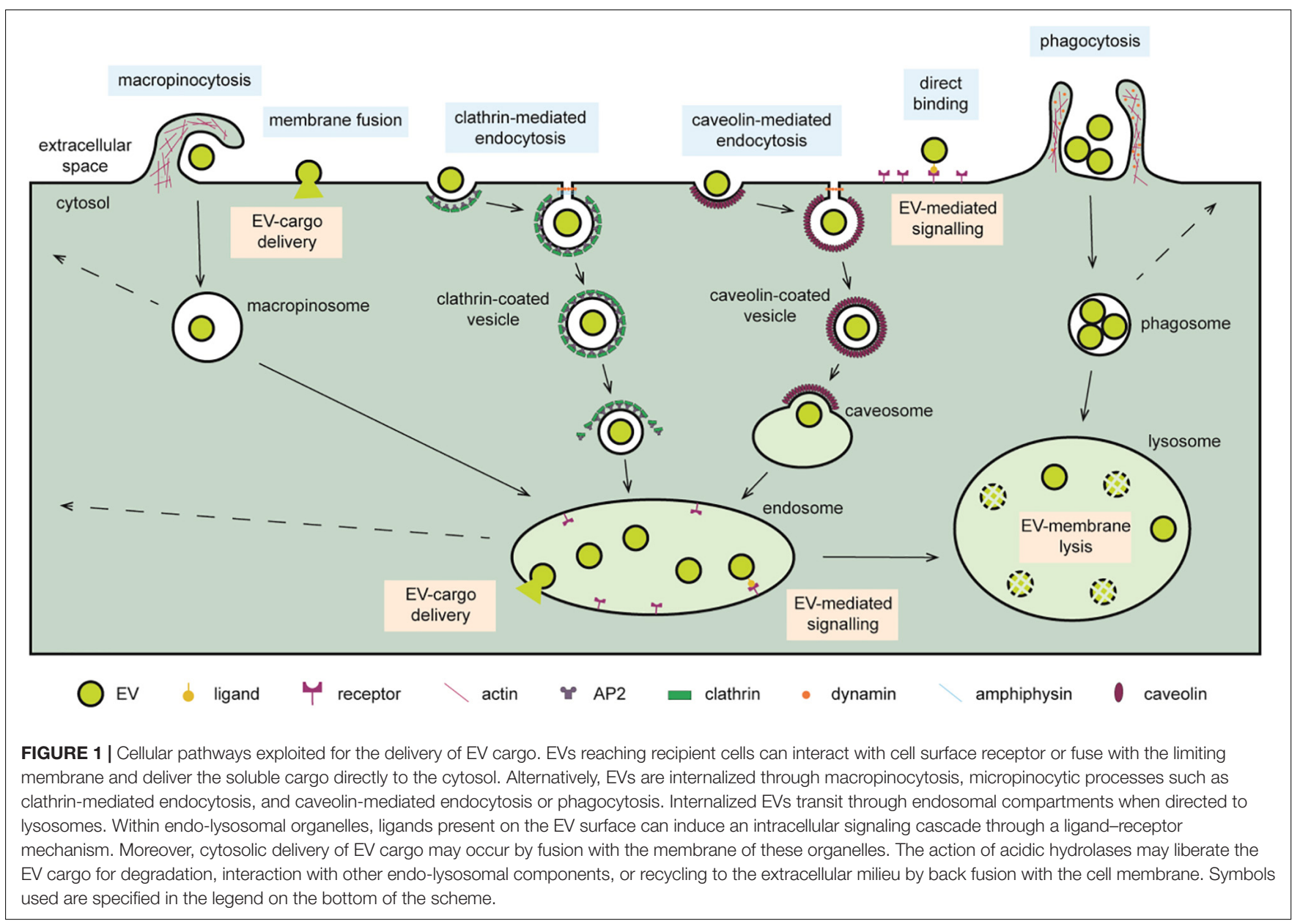

and it requires ligand-receptor-mediated recognition followed by the active ingestion of large extracellular particles $(>0.5 \mu \mathrm{m})$ into intracellular organelles called phagosomes. These latter are then directed to fuse with lysosomes to generate phagolysosome (Stuart and Ezekowitz, 2005; Kuhn et al., 2014; Kettler et al., 2016; Rosales and Uribe-Querol, 2017). Given the nature of this process, it is understood that phagocytes preferentially internalize large EVs, such as apoptotic bodies and ectosomes. Of particular interest is the highly selective uptake of apoptotic bodies by dendritic cells, a route that is mediated through the receptors for phosphatidylserine (PS), which is enriched on the surface of these large cell debris (Rubartelli et al., 1997; Hoffmann et al., 2001; Gasser et al., 2003). Nevertheless, also particles less than $100 \mathrm{~nm}$ in size are observed to be taken up by phagocytes (Kuhn et al., 2014; Kettler et al., 2016). This is supported by the observation that dendritic cells internalize exosomes through a process that is inhibited by latrunculin-A (Ogese et al., 2019), a potent inhibitor of phagocytosis (de Oliveira and Mantovani, 1988) acting by depolarizing actin filaments (Fujiwara and Zweifel, 2018). Likewise, exosomes derived from leukemia cell lines are taken up by a process sensitive to genetic inhibition of a key regulator of phagocytosis (DNM2), and once internalized, they localize with phagolysosome markers (Feng et al., 2010). Despite sufficient evidence for phagocytosis as an endocytic process involved in EV uptake, the exact mechanisms of small-size EVs phagocytosis, e.g., the receptor involved, remain to be elucidated. Moreover, given the nature of phagocytic cells, internalized EVs end up in organelles rich in digestive enzymes (Feng et al., 2010), thus representing a mean for their elimination, rather than a process involved in cell-to-cell communication.

\section{Pinocytosis}

Pinocytosis describes a process in which inward budding of the plasma membrane serves to internalize small amounts of extracellular fluid and dissolved particles eventually forming intracellular pinocytic vesicles. Pinocytosis is subdivided in micropinocytosis $(<0.1 \mu \mathrm{m})$ and macropinocytosis $(\sim 0.2-$ $5.0 \mu \mathrm{m}$ ) according to the size (and fate) of pinocytic vesicles and the molecular mechanism involved (Steinman, 1983; Kruth et al., 2005).

\section{Micropinocytosis}

Most receptor-bound ligands are internalized via micropinocytosis providing an efficient means for uptake of specific macromolecules (Sallusto, 1995; Banchereau and Steinman, 1998; Swanson, 2008; Mercer and Helenius, 2009; Bloomfield and Kay, 2016). The internalization of transferrin upon binding to the transferrin receptor is the 
best studied example of receptor-mediated endocytosis (Sullivan et al., 1976; Harding et al., 1983). Coupling transferrin with a fluorescent tag, a routine in monitoring micropinocytosis, showed different localization of EVs with transferrin, depending on incubation time and recipient cell type (Tian et al., 2014a; Yao et al., 2018). Micropinocytosis forms clathrin-, caveolin-, or non-clathrin/non-caveolin-coated plasma membrane pits (Steinman, 1983; Kruth et al., 2005; Kaksonen and Roux, 2018). Then, invaginated membranes pinch off to create organelles that mature and fuse with endosomes. This delivers their contents for recycling after fusion with the plasma membrane or for further transport to lysosomes (Mellman, 1996; Kirchhausen, 2000; Kaksonen and Roux, 2018).

EV size, EV origin, and recipient cell type may all play a role in deciding whether micropinocytosis entails the use of clathrin or caveolin or neither. EVs localize with markers of clathrin-mediated endocytosis (CLME) by a process sensitive to inhibitors of key effectors of this pathway. The compound pitstop 2 is a potent, but not selective, inhibitor of clathrindependent endocytosis that binds to the amino terminus of clathrin and blocks its association with amphiphysin (von Kleist et al., 2011; Dutta et al., 2012; Willox et al., 2014). CLME inhibition by pitstop 2 decreases $\mathrm{EV}$ uptake in human trophoblast cells (Holder et al., 2016) and colorectal carcinoma cells (Horibe et al., 2018). The cationic amphiphilic drug chlorpromazine inhibits the formation of clathrin-coated pits at the plasma membrane (Wang et al., 1993) and reduces the uptake of EVs in several in vitro cell culture models (Feng et al., 2010; Escrevente et al., 2011; Tian et al., 2014a; Yao et al., 2018). EV internalization is also decreased in the presence of pyrimidyn-7 and dynasore (Macia et al., 2006; McGeachie et al., 2013; Chiba et al., 2018; Verweij et al., 2019), two non-selective inhibitors of the GTPase activity of dynamin, a large GTPase involved in late stages of clathrin-coated pits formation (Sever et al., 2000; Hill et al., 2001). The genetic shRNA knockdown of clathrin adaptor protein 2 (AP2) and that of dynamin inhibit the assembly of clathrin-coated pits and result in an appreciable reduction of EV uptake (Tian et al., 2014a). While CLME is the best documented micropinocytic process for EV uptake, the involvement of caveolin-mediated endocytosis (CAME) becomes increasingly evident. Because of the small size of the caveolae, it is plausible to assume that CAME tends to internalize EVs with a small 60-80 nm diameter (Wang et al., 2009; Parton and Collins, 2016). The endogenous expression of caveolin-1, the main structural protein of caveolae, fluctuates between cancer cell lines and correlates with the degree of EV uptake (Horibe et al., 2018). In support to this, specific shRNA knockdown of caveolin-1 impairs EV internalization (Nanbo et al., 2013). Sterol-binding compounds that disrupt lipid rafts and caveolae structures, such as filipin, genistein, and nystatin, inhibit CAMEmediated EV uptake in various cell types (Svensson et al., 2013; Tian et al., 2014a; Lin et al., 2018; Yao et al., 2018; Harischandra et al., 2019). As dynamin also participates to the formation of caveolae at the plasma membrane (Oh et al., 1998), studies assessing the role of this protein through the use of genetic and pharmacological inhibitors do not discern the possible involvement of CLMA and CAME.
Taken together, the evidence that micropinocytosis is implicated in the internalization of small-size EVs is well documented. However, some of the molecular mechanisms involved in this process need more investigation, in particular the selective tropisms toward subclasses of small-size EVs.

\section{Macropinocytosis}

Macropinocytosis, on the other hand, overcomes the size limitation in EV internalization of micropinocytic processes. Macropinocytosis is characterized by the formation of actin-rich plasma membrane extensions, named ruffles (Swanson and Watts, 1995; Kerr and Teasdale, 2009). These pockets-like membrane structures fuse back with the plasma membrane and pinch off to form non-coated organelles, referred to as macropinosomes, which encapsulate a large volume of extracellular material (Kerr and Teasdale, 2009). The relatively large size of macropinosomes allows the uptake of a greater load of EVs and a broader range of EV sizes when compared to micropinosomes. As for most endocytic organelles, macropinosomes mature, shrink, and move toward the center of the cell where they eventually fuse with lysosomes. Although rarely, these organelles can recycle back to the plasma membrane and release their content in the extracellular space (Swanson and Watts, 1995). Macropinocytosis is an efficient, although non-selective, mechanism for internalizing EVs (Swanson and Watts, 1995). To demonstrate the participation of this pathway in the EV uptake, various inhibitors targeting the machinery generating macropinosomes were employed (Swanson and Watts, 1995; Swanson, 2008; Kerr and Teasdale, 2009; Lim and Gleeson, 2011). Macropinocytosis is dependent on the $\mathrm{Na}^{+} / \mathrm{H}^{+}$exchanger (NHE) activity (Swanson and Watts, 1995; Koivusalo et al., 2010). EIPA (5-( $N$-ethyl- $N$-isopropyl)amirolide) is an inhibitor of NHE that impairs micropinocytosis and EV uptake (Tian et al., 2014a; Costa Verdera et al., 2017). Other non-selective compounds are applied to study macropinocytosis. Wortmannin and LY294002 (Feng et al., 2010; Tian et al., 2014a; Costa Verdera et al., 2017), potent inhibitors of phosphoinositide 3-kinases, impair intracellular membrane traffic and endocytosis (Araki et al., 1996). Latrunculin-A and cytochalasin-D destabilize actin filaments (Lamaze et al., 1997; Yarmola et al., 2000; Veltman et al., 2016) and inhibit ruffles formation (Montecalvo et al., 2012; Svensson et al., 2013; Emam et al., 2018). As macropinocytosis shares with phagocytosis similar molecular mechanisms, the use of inhibitors is not sufficient to infer on the specific involvement of either processes. Colocalization of EVs with fluorescently tagged dextran, a fluid-phase marker of endocytosis, is consistent with this view (Kerr and Teasdale, 2009; Fitzner et al., 2011; Tian et al., 2014a; Costa Verdera et al., 2017; Canton, 2018). Moreover, macropinocytosis does not specifically target molecules in the extracellular environment, indicating that EV uptake may be dictated just by their proximity to the cell membrane. Nevertheless, macropinocytosis is regulated by specific mechanisms (Bryant et al., 2007; Ha et al., 2016; Colin et al., 2019); stimulation, e.g., of the epidermal growth factor receptor, enhances EV uptake (Nakase et al., 2015; Colin et al., 2019). Notably, also EVs appear to induce macropinocytosis (Costa Verdera et al., 2017). 
Similar to phagocytosis, macropinocytosis channels EVs to lysosomes (Fitzner et al., 2011; Yao et al., 2018), possibly indicating a clearance mechanism, rather than a route for transcellular signaling.

\section{DELIVERING AN EV CARGO: MEMBRANE FUSION}

Cells exploit EVs to communicate biological information over short and long distances, implying that the message transported by EVs must engage with its natural target. This may occur at the cell surface excluding an internalization process (Shelke et al., 2019), e.g., when B-lymphocyte EVs activate T-cell receptors on the surface of lymphocytes (Raposo et al., 1996). In contrast, for a cargo such as RNAs transported in the EV lumen, the target enabling a biological response is likely to be located in the nuclear-cytosolic compartment where the machineries for, e.g., mRNA translation or for microRNA regulation are expected (Valadi et al., 2007; Zomer et al., 2015). However, there is a lack of knowledge on the cell biology and biochemistry allowing the EV cargo to bypass the robust barriers imposed by the phospholipid bilayers, limiting both EVs and recipient cells. Not surprisingly, the direct fusion of EVs with the membranes of recipient cells is proposed as a relatively simple process for cell entry (Parolini et al., 2009; Zomer et al., 2015; Prada and Meldolesi, 2016; Van Dongen et al., 2016). Given the large body of evidence for an EV uptake by endocytosis before cargo delivery, it is conceivable that endocytic organelles may act as the location where EVs fuse with cell membrane, in a process known as "endosomal escape." In this sense, recent studies offer a reasonable mechanism of membrane fusion facilitated by the acidic environment and by the degradative activity of lysosomal hydrolases (Parolini et al., 2009; Montecalvo et al., 2012; Joshi et al., 2020). This is reminiscent of the process used by several virus to deliver genomic material to the host cell (Burkard et al., 2014). Indeed, low pH and acidic hydrolases may induce conformational changes in viral fusion proteins that facilitate the merge with the cell membranes (Burkard et al., 2014; Staring et al., 2018). This is the case for the rabies virus glycoprotein (RVG), which binds to the nicotinic acetylcholine receptor expressed by cells of the nervous system (Lentz et al., 1982; Gaudin et al., 1993; Lafon, 2005).

Interestingly, liposomes and other types of synthetic EVs are developed as vectors for the delivery of membrane-impermeable drugs, whereby multiple solutions were designed to improve endosomal escape. The engineering of EVs bearing a short peptide derived from RVG efficiently delivers functional BACE1 siRNA to neuronal cells in the mouse brain (Alvarez-Erviti et al., 2011). Similarly, the integrin-recognition motif ArgGly-Asp (RGD), present on viral envelopes, mediates host cell infection (Hussein et al., 2015) by driving viral particle internalization and endosomal escape (Shayakhmetov et al., 2005). Incorporation of LAMP2 fused to RGD in the membrane shield of EVs results in an efficient EV delivery of the chemotherapeutic doxorubicin to integrin-positive breast cancer cells (Tian et al., 2014b). Lipids participate as well in membrane fusion events (Mathieu et al., 2019). For instance, PS on the EV surface may interact with the PS-ligand annexin-V enriched in membranes of early and late endocytic organelles of macrophages (Diakonova et al., 1997). In an opposite manner, PS on the luminal side of endocytic membranes (Matsudaira et al., 2017) binds to annexin-V present on the surface of apoptotic bodies (Igami et al., 2020). Cholesterol is a key component of membrane organization and fusion events (Yang et al., 2016). Indeed, the incorporation of cholesterol in EV membranes is tightly regulated, and the endocytic process largely depends on cholesterol (Mulcahy et al., 2014; Pfrieger and Vitale, 2018; Mathieu et al., 2019; Skotland et al., 2020). A recent report describes that treatment with U18666A, a ligand of Niemann-Pick C1 protein, causes endo-lysosomal accumulation of low-density lipoprotein-bound cholesterol and hampers EVs fusion with recipient cell membranes (Joshi et al., 2020). In a more provocative way, the description of an unconventional delivery of EV content directly into the nucleus of recipient cells mediated by late endosomes in contact with the nuclear envelope unveils a beforehand unexplored EV delivery mechanism (Rappa et al., 2017).

Independently of the mechanisms involved, the fusion of EVs with cell membranes is expected to result in the liberation of EV luminal cargos within the cytosol of the recipient cell. Several studies have exploited the extremely sensitive CRE-based recombination technique to infer on EV-mediated trans-cytosol transport of biologically active macromolecules. Strikingly, these studies reveal that cytosolic entry of an EV cargo occurs at a sporadic rate (Ridder et al., 2014, 2015; Zomer et al., 2015; Sterzenbach et al., 2017; Steenbeek et al., 2018; Ilahibaks et al., 2019), an observation in contradiction with the large body of evidence showing an efficient EV uptake through endocytosis.

\section{THE ENDO-LYSOSOMAL SYSTEM, A CROSSROAD FOR EXOGENOUS AND ENDOGENOUS BIOMOLECULES?}

The molecular mechanisms governing EV cargo loading dictate not only the specific cargo signature of an EV and thus the specific effect it will elicit in recipient cells, but also the preferential route of delivery (van Niel et al., 2018). Among all the identified biomolecules transported within the EV lumen (Colombo et al., 2014), nucleic acids and proteins have been shown to elicit a response in recipient cells (Valadi et al., 2007; Skog et al., 2008; Zomer et al., 2015). The target machinery able to translate a nucleic acid-encoded message is expected within the cytosol or the nucleus of recipient cells, with delivery requiring membrane fusion events. A different prospect applies for a protein cargo, as various surface and intracellular targets are apt for engagement, thus widening the possible location for the delivery of the message. Additional intracellular locations besides the cell surface and the cytosol, discussed above, are plausible. Recent studies imply an EV-mediated signaling in the endo-lysosomal compartment. Human mast cell-derived EVs promote phenotypic changes in recipient mesenchymal stem cells through transforming growth factor beta1 (TGFbeta1) 
signaling (Shelke et al., 2019). The role of endosomes in this signaling is demonstrated by requirement of an acidic $\mathrm{pH}$ for the activation of TGFB1 (Annes et al., 2003; Shelke et al., 2019). EVs loaded with the enzyme beta-glucocerebrosidase (GBA) cause increased lysosomal GBA activity in recipient cells to a similar extent when GBA was engineered in the lumen or on the surface of EVs (Do et al., 2019a). These data indicate that macromolecules transported through EVs could remain functionally active in organelles of the endo-lysosomal pathway. Endo-lysosome organelles represent a subcellular compartment where degradative pathways able to transfer exogenous and endogenous proteins converge (Lawrence and Zoncu, 2019). In other words, the endo-lysosomal compartment represents a crossroad where extracellular molecules delivered through "cell-eating" and "cell-drinking" endocytic pathway may meet intracellular molecules transported by the "self-eating" autophagic machinery (Mizushima and Komatsu, 2011).

\section{SELF-EATING}

Protein homeostasis is maintained in mammalian cells by multiple systems (Li et al., 2012). The ubiquitin (Ub)-proteasome system (UPS) is a selective proteolytic machinery, in which (usually) short-living poly-ubiquitinated proteins are unfolded and degraded by the proteasome (Mizushima and Komatsu, 2011). The term autophagy originates from the Greek words aùtós (auto = self) and $\varphi \alpha \gamma \varepsilon \hat{i} \nu$ (phagy = eating), hence describing a self-eating process (Wesselborg and Stork, 2015). The autophagic machinery is complex in terms of both distinct mechanisms and substrate heterogeneity; this latter spanning from (usually) long-living proteins, protein aggregates, nucleic acids, and cellular organelles (Mizushima and Komatsu, 2011; Fujiwara et al., 2017). Moreover, besides its degradative function, autophagy is a truly dynamic process that serves also as a recycling system providing the cell with the material required to maintain its energetic homeostasis (Mizushima and Komatsu, 2011). The broad term "autophagy" encompasses three main processes: macroautophagy, microautophagy, and chaperone-mediated autophagy (CMA) (He and Klionsky, 2009; Tooze and Yoshimori, 2010; Feng et al., 2014; Dikic and Elazar, 2018). Macroautophagy sequesters and encapsulates cytoplasmic components including whole organelles or organelle portions within an intermediate double-phospholipid-bilayer organelle named "autophagosome" (Xie and Klionsky, 2007; Tooze and Yoshimori, 2010; Lawrence and Zoncu, 2019). This latter travels along microtubules toward the perinuclear region where it fuses either directly with lysosomes or with late endosomes as an intermediate step (Xie and Klionsky, 2007; Tooze and Yoshimori, 2010; Mizushima and Komatsu, 2011; Nakamura and Yoshimori, 2017). In contrast, microautophagy sequesters small components of the cytoplasm (Mijaljica et al., 2011). Non-selective microautophagy is specific toward small cytosolic substrates, e.g., soluble proteins, and is characterized by the formation of tubular invaginations of the lysosomal membranes (Mijaljica et al., 2011; Li et al., 2012). These membrane invaginations pinch off, forming intralysosomal vesicles, which then release their cargo in the hydrolaserich environment of lysosomes (Sahu et al., 2011). Inward membrane budding is also at the basis of ILV biogenesis in MVBs, a process that may be suitable for eliminating cytosolic components by secretion. On the other hand, selective microautophagy is specific toward large substrates or organelles (e.g., mitochondria, nucleus, and peroxisomes). These are engulfed through the projected, arm-like protrusion of lysosomal membranes; internalized within the lumen of lysosomes; and then gradually digested (Mijaljica et al., 2011; Mizushima and Komatsu, 2011; Li et al., 2012). Unlike the other two types of autophagy, in CMA the combined action of the chaperone protein heat shock cognate 70 (HSC70) and the lysosomes-associated membrane protein type 2A (LAMP2A) results in the specific recognition of protein substrates carrying a KFERQ-like pentapeptide and in their active translocation across lysosomal membranes (Mizushima et al., 2008; Orenstein and Cuervo, 2010; Mizushima and Komatsu, 2011; Mizushima, 2018; Figure 2).

Autophagy is thus a diversified system that continuously delivers a large variety of intracellular substrates to the endolysosomal compartments. In this way, it is a process that, at any given time, expands the array of macromolecules available to meet extracellular material internalized through endocytosis, with possible implications in health and disease. Notably, EV cargos such as mRNAs and miRNAs may directly regulate the autophagic processes once released within recipient cells (Song et al., 2016; Cai et al., 2017; Kulkarni et al., 2018). This encounter, within an acidic compartment dedicated to degradation, may gain relevance in cellular states where lysosomal activity is compromised, and substrates may accumulate.

\section{AUTOPHAGY-LYSOSOME DYSFUNCTION IN NEURODEGENERATIVE DISEASES}

Neurodegenerative disorders, such as AD, Parkinson disease (PD), Huntington disease (HD), amyotrophic lateral sclerosis (ALS), and transmissible spongiform encephalopathies (TSEs), are etiologically and clinically distinct. Crucially, they all share as pathological hallmark the deposition of protein aggregates into ubiquitinated intraneuronal inclusions (Brundin et al., 2010; Ciechanover and Kwon, 2015). Each disorder-specific protein aggregate is formed by distinct proteins, which acquire a beta-sheet-enriched conformation and eventually form soluble multimeric structures and insoluble protein inclusions. Betaamyloid and tau are linked to AD (Terry, 1963; Masters et al., 1985; Grundke-Iqbal et al., 1986; Goate et al., 1991; Haass and Selkoe, 1993), alpha-synuclein to PD (Polymeropoulos et al., 1997; Uversky, 2007), huntingtin to HD (Davies et al., 1997; DiFiglia et al., 1997), TDP43 to ALS, and frontotemporal lobar degeneration (FTLD) (Arai et al., 2006; Neumann et al., 2006) and prion to TSE (Aguzzi, 2007). A recognized risk factor for this family of disorders is aging, as well as the gradual impairment of the cellular degradative systems (Kovács et al., 2007; Piras et al., 2016; Malik et al., 2019). Postmitotic neurons 


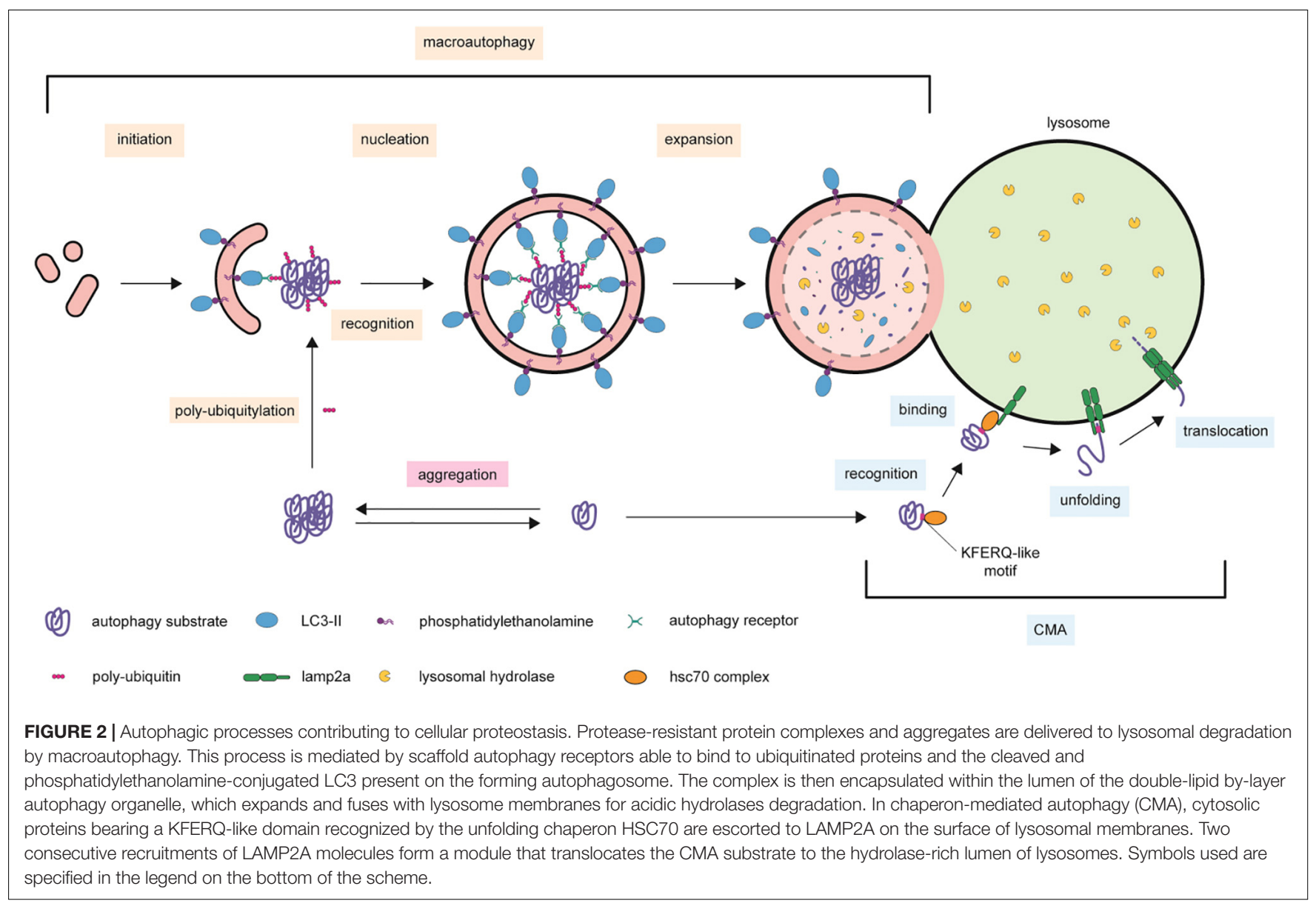

of the central nervous system are particularly vulnerable to the impairment of the autophagy-lysosome pathway. This agedependent progressive deficiency observed in the aging brain correlates with the increasing accumulation of potentially toxic protein forms in the neurodegenerating brain (Wong and Cuervo, 2010; Lamark and Johansen, 2012; Ciechanover and Kwon, 2015; Metaxakis et al., 2018). This is further supported by animal models of late-onset neurodegenerative disorders, which display a progressive accumulation of autophagic organelles and protein aggregates (Spencer et al., 2009; Decressac et al., 2013; Valionyte et al., 2020). Furthermore, nanoscale analysis performed on postmortem brain tissue slice of patients affected by $\mathrm{AD}$ and $\mathrm{PD}$ showed that beta-amyloid and alpha-synuclein inclusions were enriched in lipid membranes and organelles structurally resembling lysosomes and in part immune-reactive for lysosomal markers (Nixon et al., 2005; Hassiotis et al., 2018; Shahmoradian et al., 2019). Similar observations were made with the identification of intralysosomal prion inclusions in neurons of sporadic Creutzfeldt-Jakob disease brains (Kovács et al., 2007). Actually, most studies demonstrated that cytosolic protein inclusions are substrates of selective macroautophagy and that molecular interventions aimed to stimulate macroautophagy reduce intraneuronal protein deposition with concomitant decrease in cell toxicity and amelioration in behavioral phenotypes in animal models
(Tanaka et al., 2004; Spencer et al., 2009; Caccamo et al., 2010; Spilman et al., 2010; Yang et al., 2011; Steele et al., 2013; Savolainen et al., 2014; Yoon et al., 2017; Djajadikerta et al., 2019). Intuitively, a defect in a key clearance mechanism of the cell is expected to directly contribute to the build-up of aberrant proteins predestined to be eliminated. On the other hand, cellular inclusions and lysosomal overload may contribute to a vicious cycle of events curbing lysosomal dysfunction and protein deposition. Nevertheless, the discussion whether defective activity of the autophagy-lysosome pathway is a "cause" or an "effect" of intracellular protein inclusions merits more attention (Figure 3).

\section{The "Cause"}

Compelling genetic and pharmacological experimental evidence supports that impairment of the autophagy-lysosome pathway exacerbates the accumulation of potentially toxic protein oligomers and causes neurodegeneration. To reinforce this argument, an approach often used is to abolish or reduce the transcription of genes belonging to the core machinery of autophagy. The autophagy-related 5 (ATG5) gene encodes for a protein that conjugates with ATG12 and ATG16 to form a complex involved in the extension of autophagosome membranes (Tanida, 2011). Mice lacking Atg5 expression specifically in neurons are characterized by the progressive 


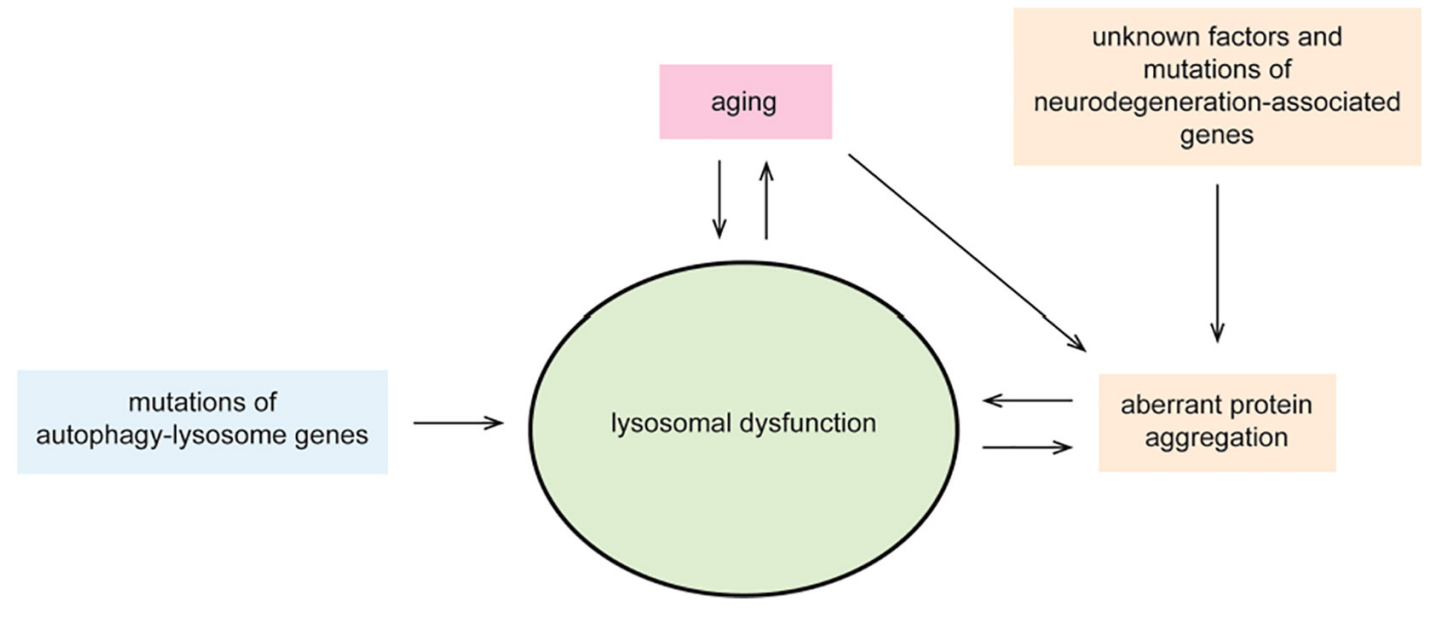

FIGURE 3 | Lysosomal dysfunction in neurodegeneration. Controlled degradation of proteins via lysosomal hydrolases is a key cellular homeostatic event. Aging, unknown factors, mutations in neurodegeneration-associated genes and in autophagy-lysosome genes, and the accumulation of cytosolic protein inclusions are negative regulators of lysosomal function. In a vicious circle, defective lysosomal function contributes to aging, accumulation of toxic gene products, and disease. Impaired lysosomal function may occur at the level of acidic hydrolase activity or by altered fusion and maturation of autophagy-lysosome organelles.

neuronal accumulation of cytoplasmic, Ub-positive inclusion bodies and by the concomitant progressive deficit in motor and behavioral functions (Hara et al., 2006). ATG7 is an E1-like activating enzyme whose primarily function is to participate in the conjugation of ATG12 and in the lipidation of the microtubule-associated protein light chain 3 (LC3), two essential steps in the formation of functional autophagosomes (Xiong, 2015). The study of Atg7 knockout mice provides additional evidence for the contribution of autophagy in the formation of protein inclusions with aberrant intraneuronal accumulation of beta-amyloid and cognitive dysfunction in a mouse model of AD (Nilsson et al., 2013). Beclin-1, another regulator of macroautophagy, appears altered in aged brains and in patients affected by $\mathrm{AD}$ and $\mathrm{HD}$. Decreased beclin1 in mice models of $\mathrm{AD}$ - and HD-related amyloidosis causes impaired macroautophagy, increased inclusion bodies, and general neuronal deficits, aspects reversed through ectopic beclin-1 expression (Shibata et al., 2006; Pickford et al., 2008; Lucin et al., 2013).

To date, there is only a single report of a human pathogenic mutation among all the core ATG genes. The homozygous E122D mutation in ATG5 was found in two siblings affected by a childhood form of ataxia, characterized by progressive loss of Purkinje cells, cerebellar hypotrophy, and clinical symptoms affecting muscle coordination (Kim et al., 2016). At the cellular level, the single point mutation leads to impaired autophagy flux caused by defective conjugation of ATG5 with ATG12 (Kim et al., 2016).

Selective macroautophagy depends on Ub-binding scaffold proteins that recognize cytoplasmic ubiquitinated protein substrates and deliver them to the autophagy pathway for degradation (Zientara-Rytter and Subramani, 2019). Among all, P62/sequestome 1 (encoded by the SQSTM1 gene), NBR1 autophagy receptor (NBR1, neighbor of BRCA1 gene), autophagy-linked FYVE protein ALFY (WDFY3), and optineurin (OPTN) are found in almost all types of protein aggregates (Pankiv et al., 2007; Stolz, 2014; Lim and Yue, 2015). The presence of autophagy receptors within cytoplasmic inclusions supports the view that protein aggregates are cleared by a selective macroautophagic process (aggrephagy) (Øverbye, 2007). Concomitantly, the presence of autophagy receptors within cytoplasmic inclusions is also linked to a role of these as facilitators of protein aggregation (Pankiv et al., 2007; Shen et al., 2015). Most autophagy receptors are scaffold proteins that carry an Ubassociated (UBA) domain and an LC3-interacting region (LIR). The UBA domain binds to mono-ubiquitinated and poly-ubiquitinated proteins (Shaid et al., 2013; Stolz, 2014; Deng et al., 2017). On the other hand, the LIR sequence binds to LC3 conjugated to the inner surface of the phagophore (LC3-II), thus mediating the encapsulation of the complex in autophagosomes (Stolz, 2014; Deng et al., 2017; Dikic and Elazar, 2018), whereby autophagy receptors and LC3II become themselves autophagy substrates (Deng et al., 2017). Genetic variants of the autophagy receptors OPTN and SQSTM1 are linked to ALS-FTLD (Fecto et al., 2011; Deng et al., 2017), and more severe disease forms are caused by mutations in the UBA domain of P62 (Fecto et al., 2011; Kwok et al., 2014). Furthermore, P62, optineurin, and NBR1 localize within Lewy bodies and neurofibrillary tangles (NFTs) in postmortem human brain tissue (Osawa et al., 2011; Odagiri et al., 2012). At the cellular level, P62 binds to polyubiquitinated tau mediating its clearance, and mice with genetic Sqstm1 inactivation display intraneuronal tau aggregation (Ramesh Babu et al., 2008).

Inherited mutations of lysosomal hydrolases are linked to neurodegenerative disorders (Lwin et al., 2004; Osellame et al., 2013; Ebrahimi-Fakhari et al., 2014; Menzies et al., 2017; Do et al., 2019b). For instance, homozygous mutation in the GBA gene encoding for the lysosomal enzyme glucocerebrosidase 
causes Gaucher disease, a lysosomal storage disorder (Mazulli et al., 2011; Menzies et al., 2017; Do et al., 2019b). Loss of GBA function triggers the accumulation of its substrate glucocerebroside within lysosomes leading to dysfunctional lysosomal degradation and autophagic processes (Mazulli et al., 2011; Menzies et al., 2017; Do et al., 2019b). Experimental Gba knockout mouse model of Gaucher disease displays defective autophagy with P62 accumulation, Ub-positive proteins, and oligomeric alpha-synuclein (Osellame et al., 2013). Notably, heterozygous mutation in $G B A$ is the most common genetic risk factor for PD (Lwin et al., 2004; Menzies et al., 2017; Do et al., 2019b).

Chemical compounds are also used to mimic autophagy dysfunction and its consequences. Bafilomycin A1, a macrolide derived from Streptomyces griseus, specifically inhibits the vacuolar ATPase that transports protons to the interior of acidic organelles (Mauvezin and Neufeld, 2015). Chloroquine (CQ), a drug known for its antimalarial and anti-inflammatory properties, is a lysosomotropic buffering agent rapidly penetrating across cell membranes and undergoing a protonation-based trapping in the acidic environment of autophagic, endocytic, or lysosomal organelles (Al-Bari, 2015). The presence of either compound efficiently neutralizes the luminal $\mathrm{pH}$, inhibits acidic hydrolases, and impairs the fusion among acidic organelles (Yamamoto et al., 1998; Mauvezin and Neufeld, 2015; Mauthe et al., 2018). Increased accumulation of cytosolic aggregates is found when these drugs are applied to in vitro and in vivo models of neurodegeneration. This occurs, for instance, in COS-7 cells expressing an aggregationprone fragment of mutant huntingtin, where treatment with bafilomycin A1 results in a more pronounced aggregation determined by the increase in aggregates size and in the number of affected cells (Ravikumar et al., 2002). The same treatment exacerbates the formation of detergent-insoluble alpha-synuclein species in rat embryonic cortical neurons (Lee et al., 2004). An increment in seeding events is observed in primary neurons derived from tau transgenic mice when incubated with exogenous tau fibrils and CQ (Gibbons et al., 2017). A higher Ub-positive cytoplasmic TDP43 inclusion load is observed upon CQ treatment of a mouse model expressing mutated vasolin-containing protein (Custer et al., 2010; Nalbandian et al., 2015). In good agreement with these findings, macroautophagy stimulation is a proven intervention apt to reduce cytosolic protein aggregates, ultimately reversing behavioral phenotypes in animal models of neurodegenerative diseases (Ravikumar et al., 2004; Tanaka et al., 2004; Spencer et al., 2009; Caccamo et al., 2010; Spilman et al., 2010; Yang et al., 2011; Steele et al., 2013; Savolainen et al., 2014; Yoon et al., 2017; Djajadikerta et al., 2019). In a mouse model of beta-amyloid and tau pathology, induction of autophagy with an inhibitor of the mammalian target of rapamycin (mTOR) decreases intraneuronal beta-amyloid accumulation and rescues cognitive deficits (Caccamo et al., 2010). Similarly, oral administration of the disaccharide trehalose in a transgenic mouse model for mutant huntingtin effectively reduces cytosolic inclusions and ameliorates hallmark motor dysfunctions of HD (Tanaka et al., 2004). The neuroprotective effect of trehalose may rely on stimulation of autophagic flux independently from the mTOR signaling pathway (Sarkar et al., 2007; Lee et al., 2018).

\section{The "Effect"}

The increased impairment of the autophagy-lysosome pathway associated with the progression of neurodegenerative disorders may hint to intrinsic negative effects caused by accumulating aberrant protein forms. This outcome may result from a loss of function; e.g., the scaffold protein huntingtin interacts with P62 and facilitates the association of ubiquitinated substrates targeted to autophagy with LC3 (Ochaba et al., 2014). Mutant huntingtin fails in this role, thus compromising cytosolic cargo recognition and delivery to selective autophagy (Martinez-Vicente et al., 2010).

UPS and CMA are the first-line defense in disposing soluble proteins. However, when proteins aggregate into fibrillar insoluble forms, as it is the case for neurodegenerative disorders, they become increasingly resistant to both UPS and CMA degradation (Ciechanover and Kwon, 2015). The capacity to "escape" UPS and CMA degradation may well rely on the resilience of structured, beta-sheet-enriched protein aggregates to chaperon-mediated "unfolding," which is required for funneling the polypeptide into these degradative pathways. As a result, they may act as negative regulators. CMA-mediated degradation relies on the presence of the KFERQ-like motif on its substrates. Accordingly, the VKKDQ sequence on alphasynuclein is a recognition and binding domain for the chaperon HSC70, which mediates its translocation into lysosomes (Fred Dice, 1990; Cuervo et al., 2004). Fibrillar forms of alphasynuclein resist to the unfolding activity of HSC70, and by binding to LAMP2A, they act as translocation inhibitors further busting their accumulation and impairing the degradation of other CMA substrates (Cuervo et al., 2004; Ross and Poirier, 2005). Likewise, at least in vitro, cytosolic protein inclusions act as clogging blockers in the barrel-shaped structure of the proteasome (Cuervo et al., 2004; Martinez-Vicente et al., 2008; Andre and Tabrizi, 2012). However, UPS and CMA impairment stimulates the specialized activity of aggrephagy as an alternative degradative machinery (Massey et al., 2006; Pandey et al., 2007; Lamark and Johansen, 2012).

Interestingly, prion infection disrupts the maturation of endolysosomal organelles by interfering with RAB7 association to membranes, which eventually prevents lysosomal degradation of $\operatorname{PrP}^{\mathrm{Sc}}$ in favor of fibril formation (Shim et al., 2016). The key molecular spark that triggers prion pathogenesis is the conformational conversion of prion protein $\operatorname{PrP}^{C}$, with a predominant alpha-helix content, into the highly infectious beta-sheet-rich $\mathrm{PrP}^{\mathrm{Sc}}$ (Pan et al., 1993). $\mathrm{PrP}^{\mathrm{Sc}}$ forms detergentinsoluble fibrils also defined as $\operatorname{PrP}^{\text {Res }}$ to highlight their intrinsic ability to resist to proteolytic degradation. As the endo-lysosomal pathway may represent the subcellular site where the conversion to $\operatorname{Pr} \mathrm{P}^{\mathrm{Sc}}$ occurs, this has the potential to impair overall lysosomal degradative function (Caughey et al., 1991). Indeed, increased number and size of lysosomes and autophagic vacuoles are well-established neuropathological features of prion-infected neurons in animal models and in patients (Boellaard et al., 1991; Sikorska et al., 2004). 
In addition to the effect of cytosolic aberrant protein forms, also their extracellular counterparts need to be considered when studying the pathogenesis of diseases. As previously discussed, non-cell-autonomous proteins exploit the endocytic pathway to access the inside of cells. In this respect, recombinant and brain-extracted protein fibrils and seeds enter the cell and traffic toward lysosomes upon endocytosis (Hu et al., 2009; Domert et al., 2016; Karpowicz et al., 2017; Evans et al., 2018), whereby lysosomal function appears required prior to reach the cytosol for further propagation (Tsujimura et al., 2015; Domert et al., 2016; Evans et al., 2018; Hoffmann et al., 2019). Intriguingly, exogenous alpha-synuclein fibrils taken up by endocytosis drive intracellular seeding within the endo-lysosomal compartment (Tsujimura et al., 2015). This occurs with the assistance of the lysosomal protease cathepsin-beta that, when compared other proteases, specifically triggers its aggregation. Concurrently, the accumulation of protease resistant alpha-synuclein fibrils within lysosomes impairs lysosomal function and autophagic flux (Hoffmann et al., 2019).

\section{Protein Aggregation Within Lysosomes}

In the context of this review, it is intriguing to consider alternative intracellular locations besides the cytosol, which may serve as seeding hubs in the nucleation process leading to intraneuronal inclusions as observed in neurodegenerative disorders. The acidic organelles of the cell may represent the initial location for the seeding activity of exogenous protein oligomers and fibrils, which may then gain access to the cytosol and trigger further aggregation (Figure 4). The endo-lysosomal pathway of the cell gathers at least four features that ideally facilitate the mechanism of disease-causing protein aggregation: (1) the presence of proteases, (2) the co-assistance of other protein-modifying enzymes such as glycosidases, sulfatases, and kinases, (3) a low $\mathrm{pH}$, and (4) a relatively small volume and membrane surface area.

Proteolytic processing of neurodegeneration-associated proteins has received particular attention as in vitro evidence suggests increased propensity to aggregate when these are cleaved at specific amino acid sites. We discussed already above the evidence that in a cellular model of prion infection, the amino terminus of $\operatorname{PrP}^{\text {Res }}$, or of its precursor, is removed by lysosomal proteases facilitating its aggregation within lysosomes (Caughey et al., 1991). It was recently reported that tau is a substrate of asparagine endopeptidase, a lysosomal cysteine protease generating tau fragments with a high propensity to aggregate (Chen et al., 1998) observed also in the brain of human AD or tau transgenic mice (Zhang et al., 2014). What is more, the release of beta-amyloid from its precursor is initiated by the activity of the acidic endoprotease BACE located in endo-lysosomes (Pasternak et al., 2004). Intriguingly, the discovery within lysosomes of kinases phosphorylating neurodegenerative-associated proteins has raised awareness that pathological phosphorylation may be acquired within these organelles. As an example, the betaisoform of glycogen synthase kinase 3 (GSK3beta), the main phosphorylating enzyme for a tau form enriched in diseaseassociated NFTs (Cohen and Goedert, 2004), is found within acidic organelles of the endo-lysosome pathway (Taelman et al.,
2010; Li et al., 2016). Although experimental evidence that directly links tau toxicity to lysosomal GSK3beta is missing, this mechanism is intriguing and cannot be disregarded.

A high load of energy is required for the activity of the proton pump to maintain the acidic conditions required for the activity of lysosomal enzymes (Mindell, 2012). A low pH could serve as a spark triggering protein aggregation as it was shown for prion conversion (DeMarco and Daggett, 2007; Srivastava and Lapidus, 2017). Indeed, a protonation-based model approach demonstrated that the partial unfolding and dissociation of one alpha-helices of $\mathrm{PrP}^{\mathrm{C}}$ result in the loss of critical longrange salt bridges, which favor the conversion to a $\mathrm{PrP}^{\mathrm{Sc}}$-like structure (DeMarco and Daggett, 2007). Similar results were obtained analyzing kinetics of amyloid fibril formation, which is accelerated in the $\mathrm{pH}$ range observed in lysosomes of living cells, implying a possible contribution of lysosomes in amyloid diseases (Colon and Kelly, 1992).

The relatively small size of endo-lysosomal organelle when compared to the cytosol should also be considered a critical contributor of neurotoxic protein aggregation. Seeding aggregation of proteins is remarkably dependent on protein concentration and on the interaction with membranes (Eisele et al., 2015; Poulson et al., 2020), whereby a threshold concentration has to be reached in order to initiate a nucleation-dependent polymerization (Harper and Lansbury, 1997). Autosomal dominant disease forms bring clinical evidence of the correlation between protein concentration and pathogenicity. Examples are a hereditary PD form characterized by the triplication of the alpha-synuclein locus and extensive Lewy body formation (Singleton et al., 2003) or trisomy 21 characterized by an extra copy of the $A P P$ gene and early-onset AD-like amyloidosis (Lott and Head, 2019). In vitro experiments support the view that lysosomes may foster the critical concentration and exposure to membranes required for protein nucleation and further multimerization. This is the case when extracellular betaamyloid monomers were found to be taken up by cells and to accumulate with seeding nucleation properties within lysosomes (Hu et al., 2009).

\section{Disease Spreading and EVs}

Neurodegenerative diseases are characterized by the spreading of pathological protein forms following a predictable spatiotemporal pattern through the brain of affected patients. This correlates with the symptom progression in a disorderspecific and unique manner. For instance, in AD, tau NFTs first occur in the entorhinal region and then spread to the surrounding hippocampal area and reach the entire neocortex in later disease stages (Goedert, 2015; Kaufman et al., 2018). In contrast, beta-amyloid senile plaques are first observed in the orbitofrontal and basal temporal neocortex and then slowly progress from anterior to posterior areas to invade the entire neocortex, the hippocampus, the amygdala, and the basal ganglia (Goedert, 2015). At the cellular level, nucleation-competent seeds are transferred from cell-to-cell, possibly exploiting existing cell communication mechanisms to drive the spreading of pathology. At the molecular level, the conversion of a native 


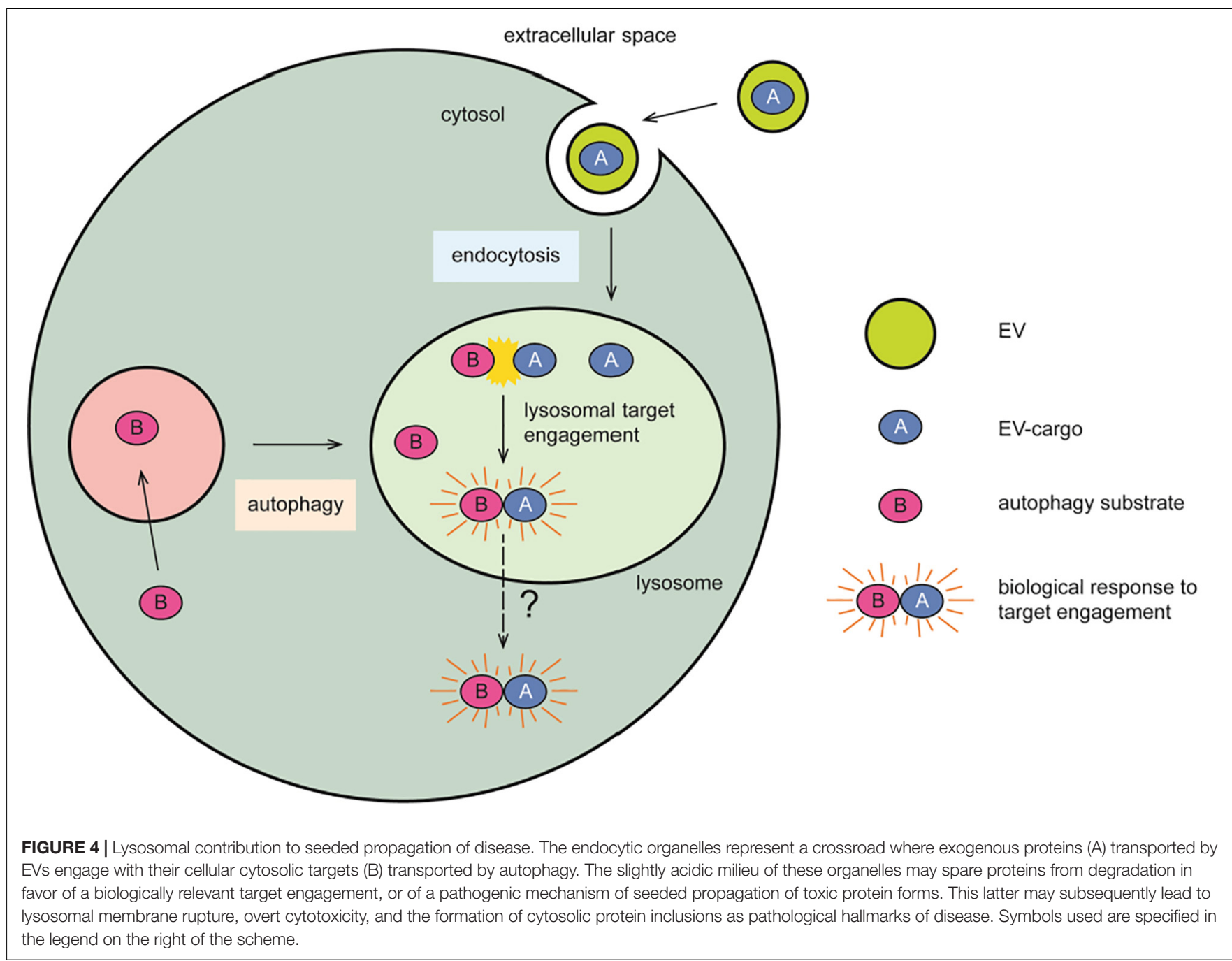

(often unfolded) state to a highly ordered fibrillar structure resembles the template-mediated mechanisms of prions, thus defined as prion-like paradigm (Soto and Pritzkow, 2018). In vitro studies support the notion that the dissemination of pathogenic protein forms through templated amplification occurs via interconnected neurons (Gribaudo et al., 2019; Hallinan et al., 2019), which fits well the progressive spreading through anatomically linked brain regions observed in vivo (Narasimhan et al., 2017; Henderson et al., 2019; Wegmann et al., 2019). Noteworthy, some connected brain areas are spared by this process, hinting to a specific cellular mechanism of release/uptake of protein seeds. Among the non-exclusive routes of cell-to-cell seed transport, EVs have gained a significant recognition as likely transcellular vehicles (Fiandaca et al., 2015; Thompson et al., 2016; Guix et al., 2018), with the advantage to ensure protection against degradative activities and propagation to distant targets. This pathogenic role of EVs is supported by observations made in animal models of most neurodegenerative disorders (Vella et al., 2007; Watson et al., 2019). Not surprisingly, there is the demand to better define whether a specific mechanism exists for the encapsulation of nucleation-competent particles into EVs by the (infectious) donor cell. At the same time, and possibly more importantly, we need to understand how seeds are internalized by the (healthy) recipient cell to reach their target. As discussed above, EVs mainly take advantage of the endocytic pathway to enter the cell where they may accumulate within lysosomes and liberate their possibly noxious cargo. Accordingly, a recent in vitro study from our laboratory brought evidence that it is conceivable that an EV-transported, proaggregating tau form uses this route of cell entry to eventually induce cellular tau accumulation within acidic organelles of the recipient cell. The physical interaction between exogenous seeds and endogenous wild-type tau at the crossroad between the endocytic and the autophagic pathways ultimately triggered the formation of tau epitopes typical of NFTs, progressive lysosomal impairment, and overt cytotoxicity (Pedrioli et al., 2020). Thus, despite the dichotomy of degradative organelles embodying the cellular site where seeded propagation of pathogenic protein occurs, mounting experimental evidence points to a role of EVs as transcellular mediators exacerbating an (age-related) impairment of the lysosomal pathway in the neurodegenerative state. 


\section{CONCLUSION AND FUTURE DIRECTIONS}

A constantly growing knowledge on the biology of EVs has expanded the initial, but still valid, interpretation of them as a kind of garbage bag expelled by the cell, to include now for them a role as vehicle of precise cell-to-cell communication and as critical contributor to disease. Technologic advances allowed a detailed, yet in part incomplete, perception of the complexity of this variegate population of secreted vesicles. A main objective of this review is to discuss the cellular mechanisms required to elicit a biological response in the acceptor cell, while much is already known in terms of EV biogenesis in the donor cell. Among them, the list includes the specific tropism toward the recipient cell, the route evolved for their uptake, and the release mechanism for the target engagement of a biological active cargo molecule. Distinct subpopulations of EVs, their cargo signatures, and the type and state of recipient cells, to name a few, are all puzzle fragments contributing to the complexity of the picture currently assembled.

This review has focused on the experimental evidence pointing to the central role for EV-mediated cellular communication provided by the endocytic pathway. In an organism, cells are exposed, at any given time, to EVs continuously released from a wide range of cell populations, with distinct biophysical properties and cargo compositions and originating from close and distant locations. Some questions relating to the mechanisms regulating the tropism of EVs remain partially unanswered. In this plethora of EVs floating on the surrounding of a cell, how is a message delivered with accurate precision to the desired target cell? Does the endocytic pathway merely represent a route exploited by EVs to gain access to the cell, or does it provide the favorable environment for functional cargo delivery in health and disease? Will the knowledge on the biology driving viral infection of a cell facilitate the identification of the mechanisms governing EV cargo release, or do we need to implement innovative and highly sensitive research methods for this purpose? The current techniques suggest that release of an EV cargo in the cytosol of recipient cells is an existing but rather rare event. An important question to be addressed will be to define

\section{REFERENCES}

Aguzzi, M. (2007). Heikenwalder, and M. Polymenidou, Insights into prion strains and neurotoxicity. Nat. Rev. Mol. Cell Biol. 8, 552-561. doi: 10.1038/nrm2204

Al-Bari, M. A. (2015). Chloroquine analogues in drug discovery: new directions of uses, mechanisms of actions and toxic manifestations from malaria to multifarious diseases. J. Antimicrob. Chemother. 70, 1608-1621. doi: 10.1093/ $\mathrm{jac} / \mathrm{dkv} 018$

Alvarez-Erviti, L., Seow, Y., Yin, H., Betts, C., Lakhal, S., and Wood, M. J. A. (2011). Delivery of siRNA to the mouse brain by systemic injection of targeted exosomes. Nat. Biotechnol. 29, 341-345. doi: 10.1038/nbt.1807

Andre, R., and Tabrizi, S. J. (2012). Misfolded PrP and a novel mechanism of proteasome inhibition. Prion 6, 32-36. doi: 10.4161/pri.6.1.18272

Annes, J. P., Munger, J. S., and Rifkin, D. B. (2003). Making sense of latent TGFbeta activation. J. Cell Sci. 116, 217-224. doi: 10.1242/jcs.00229 "rare" in the context of a biologically relevant EV-mediated cell-to-cell communication.

Finally, we also discussed the existence of a possible vicious cycle driving a neurodegenerative process (Figure 3). Aggregation of aberrant proteins may impair autophagic and lysosomal degradative pathways, which in turn curb further protein aggregation, and importantly seeded transcellular propagation possibly mediated by EVs as vectors for direct delivery of replication-competent particles to acidic organelles of recipient cells. Even more, EVs could be the trigger for the initiation of a cascade of adverse events including prionlike propagation and lysosomal dysfunction. In this context, autophagy stimulation as a proposed intervention to reduce intraneuronal protein inclusions may backfire into a completely opposite direction. If not specifically targeted to the affected neuron, autophagy stimulation may well favor that an EV cargo with seeding capabilities could encounter and propagate on the native protein counterpart within lysosomes of healthy neurons. The potential dichotomic role of the autophagy-lysosome pathway in clearing cytosolic inclusions and contributing to transcellular propagation certainly requires further attention and experimental validation.

\section{AUTHOR CONTRIBUTIONS}

GP and PP wrote, reviewed, and edited the original draft. Both authors contributed to the article and approved the submitted version.

\section{FUNDING}

PP was funded by the Swiss National Science Foundation, the Synapsis Foundation, the Gelu Foundation, and the Mecri Foundation.

\section{ACKNOWLEDGMENTS}

We thank the whole laboratory for support and advice.

Arai, T., Hasegawa, M., Akiyama, H., Ikeda, K., Nonaka, T., Mori, H., et al. (2006) TDP-43 is a component of ubiquitin-positive tau-negative inclusionsin frontotemporal lobar degeneration and amyotrophic lateral sclerosis. Biochem. Biophys. Res. Commun. 351, 602-611. doi: 10.1016/j.bbrc.2006. 10.093

Araki, N., Johnson, M. T., and Swanson, J. A. (1996). A role for phosphoinositide 3-kinase in the completion of macropinocytosis and phagocytosis by macrophages. J. Cell Biol. 135, 1249-1260. doi: 10.1083/jcb.135.5.1249

Banchereau, J., and Steinman, R. M. (1998). Dendritic cells and the control of immunity. Nature 392, 245-252. doi: 10.1038/32588

Bloomfield, G., and Kay, R. R. (2016). Uses and abuses of macropinocytosis. J. Cell Sci. 129, 2697-2705. doi: 10.1242/jcs.176149

Boellaard, J. W., Kao, M., Schlote, W., and Diringer, H. (1991). Neuronal autophagy in experimental scrapie. Acta Neuropathol. 82, 225-228. doi: 10. 1007/bf00294449 
Brundin, P., Melki, R., and Kopito, R. (2010). Prion-like transmission of protein aggregates in neurodegenerative diseases. Nat. Rev. Mol. Cell Biol. 11, 301-307. doi: $10.1038 / \mathrm{nrm} 2873$

Bryant, D. M., Kerr, M. C., Hammond, L. A., Joseph, S. R., Mostov, K. E., Teasdale, R. D., et al. (2007). EGF induces macropinocytosis and SNX1modulated recycling of E-cadherin. J. Cell Sci. 120, 1818-1828. doi: 10.1242/jcs. 000653

Burkard, C., Verheije, M. H., Wicht, O., Van Kasteren, S. I., Van Kuppeveld, F. J., Haagmans, B. L., et al. (2014). Coronavirus cell entry occurs through the endo-/lysosomal pathway in a proteolysis-dependent manner. PLoS Pathog. 10:e1004502. doi: 10.1371/journal.ppat.1004502

Caccamo, A., Majumder, S., Richardson, A., Strong, R., and Oddo, S. (2010). Molecular interplay between mammalian target of rapamycin (mTOR), Amyloid- $\beta$, and Tau. J. Biol. Chem. 285, 13107-13120. doi: 10.1074/jbc.m110. 100420

Cai, S., Shi, G.-S., Cheng, H.-Y., Zeng, Y.-N., Li, G., Zhang, M., et al. (2017). Exosomal miR-7 mediates bystander autophagy in lung after focal brain irradiation in mice. Int. J. Biol. Sci. 13, 1287-1296. doi: 10.7150/ijbs. 18890

Canton, J. (2018). Macropinocytosis: new insights into its underappreciated role in innate immune cell surveillance. Front. Immunol. 9:2286. doi: 10.3389/fimmu. 2018.02286

Caughey, B., Raymond, G., Ernst, D., and Race, R. (1991). N-terminal truncation of the scrapie-associated form of $\operatorname{PrP}$ by lysosomal protease(s): implications regarding the site of conversion of PrP to the proteaseresistant state. J. Virol. 65, 6597-6603. doi: 10.1128/jvi.65.12.6597-66 03.1991

Chen, J. M., Rawlings, N. D., Stevens, R. A., and Barrett, A. J. (1998). Identification of the active site of legumain links it to caspases, clostripain and gingipains in a new clan of cysteine endopeptidases. FEBS Lett. 441, 361-365. doi: 10.1016/ s0014-5793(98)01574-9

Chiba, M., Kubota, S., Sato, K., and Monzen, S. (2018). Exosomes released from pancreatic cancer cells enhance angiogenic activities via dynamin-dependent endocytosis in endothelial cells in vitro. Sci. Rep. 8:11972.

Ciechanover, A., and Kwon, Y. T. (2015). Degradation of misfolded proteins in neurodegenerative diseases: therapeutic targets and strategies. Exp. Mol. Med. 47:e147. doi: 10.1038/emm.2014.117

Cocucci, E., and Meldolesi, J. (2015). Ectosomes and exosomes: shedding the confusion between extracellular vesicles. Trends Cell Biol. 25, 364-372. doi: 10.1016/j.tcb.2015.01.004

Cohen, P., and Goedert, M. (2004). GSK3 inhibitors: development and therapeutic potential. Nat. Rev. Drug Discov. 3, 479-487.

Colin, M., Delporte, C., Janky, R. S., Lechon, A.-S., Renard, G., Van Antwerpen, P., et al. (2019). Dysregulation of macropinocytosis processes in glioblastomas may be exploited to increase intracellular anti-cancer drug levels: the example of temozolomide. Cancers 11:411. doi: 10.3390/cancers11 030411

Colombo, M., Raposo, G., and Thery, C. (2014). Biogenesis, secretion, and intercellular interactions of exosomes and other extracellular vesicles. Annu. Rev. Cell Dev. Biol. 30, 255-289. doi: 10.1146/annurev-cellbio-10151 2-122326

Colon, W., and Kelly, J. W. (1992). Partial denaturation of transthyretin is sufficient for amyloid fibril formation in vitro. Biochemistry 31, 8654-8660. doi: 10.1021/ bi00151a036

Costa Verdera, H., Gitz-Francois, J. J., Schiffelers, R. M., and Vader, P. (2017). Cellular uptake of extracellular vesicles is mediated by clathrin-independent endocytosis and macropinocytosis. J. Control. Release 266, 100-108. doi: 10. 1016/j.jconrel.2017.09.019

Cuervo, A. M., Stefanis, L., Fredenburg, R., Lansbury, P. T., and Sulzer, D. (2004). Impaired degradation of mutant a-synuclein by chaperone-mediated autophagy. Science 305, 1292-1295. doi: 10.1126/science.1101738

Custer, S. K., Neumann, M., Lu, H., Wright, A. C., and Taylor, J. P. (2010). Transgenic mice expressing mutant forms $\mathrm{VCP} / \mathrm{p} 97$ recapitulate the full spectrum of IBMPFD including degeneration in muscle, brain and bone. Hum. Mol. Genet. 19, 1741-1755. doi: 10.1093/hmg/ddq050

Davies, S. W., Turmaine, M., Cozens, B. A., Difiglia, M., Sharp, A. H., Ross, C. A., et al. (1997). Formation of neuronal intranuclear inclusions underlies the neurological dysfunction in mice Transgenic for the HD Mutation. Cell 90, 537-548. doi: 10.1016/s0092-8674(00) 80513-9

de Oliveira, C. A., and Mantovani, B. (1988). Latrunculin A is a potent inhibitor of phagocytosis by macrophages. Life Sci. 43, 1825-1830. doi: 10.1016/00243205(88)90282-2

Decressac, M., Mattsson, B., Weikop, P., Lundblad, M., Jakobsson, J., and Bjorklund, A. (2013). TFEB-mediated autophagy rescues midbrain dopamine neurons from a-synuclein toxicity. Proc. Natl. Acad. Sci. 110, E1817-E1826.

DeMarco, M. L., and Daggett, V. (2007). Molecular Mechanism for Low pH triggered misfolding of the human prion protein. Biochemistry 46, 3045-3054. doi: 10.1021/bi0619066

Deng, Z., Purtell, K., Lachance, V., Wold, M. S., Chen, S., and Yue, Z. (2017). Autophagy receptors and neurodegenerative diseases. Trends Cell Biol. 27, 491-504. doi: 10.1016/j.tcb.2017.01.001

Diakonova, M., Gerke, V., Ernst, J., Liautard, J.-P., van der Vusse, G., and Griffiths, G. (1997). Localization of five annexins in J774 macrophages and on isolatedphagosomes. J. Cell Sci. 110, 1199-1213.

DiFiglia, M., Sapp, E., Chase, K. O., Davies, S. W., Bates, G. P., Vonsattel, J. P., et al. (1997). Aggregation of huntingtin in neuronal intranuclear inclusions and dystrophic neurites in brain. Science 277, 1990-1993. doi: 10.1126/science.277. 5334.1990

Dikic, I., and Elazar, Z. (2018). Mechanism and medical implications of mammalian autophagy. Nat. Rev. Mol. Cell Biol. 19, 349-364. doi: 10.1038/ s41580-018-0003-4

Djajadikerta, A., Keshri, S., Pavel, M., Prestil, R., Ryan, L., and Rubinsztein, D. C. (2019). Autophagy induction as a therapeutic strategy for neurodegenerative diseases. J. Mol. Biol. 432, 2799-2821. doi: 10.1016/j.jmb.2019. 12.035

Do, J., McKinney, C., Sharma, P., and Sidransky, E. (2019b). Glucocerebrosidase and its relevance to Parkinson disease. Mol. Neurodegener. 14:36.

Do, M. A., Levy, D., Brown, A., Marriott, G., and Lu, B. (2019a). Targeted delivery of lysosomal enzymes to the endocytic compartment in human cells using engineered extracellular vesicles. Sci. Rep. 9:17274.

Domert, J., Sackmann, C., Severinsson, E., Agholme, L., Bergström, J., Ingelsson, M., et al. (2016). Aggregated Alpha-Synuclein transfer efficiently between cultured human neuron-like cells and localize to lysosomes. PLoS One 11:e0168700. doi: 10.1371/journal.pone. 0168700

Durak-Kozica, M., Baster, Z., Kubat, K., and Stêpień, E. (2018). 3D visualization of extracellular vesicle uptake by endothelial cells. Cell. Mol. Biol. Lett. 23:57.

Dusoswa, S. A., Horrevorts, S. K., Ambrosini, M., Kalay, H., Paauw, N. J., Nieuwland, R., et al. (2019). Glycan modification of glioblastoma-derived extracellular vesicles enhances receptor-mediated targeting of dendritic cells. J. Extracell. Vesicles 8:1648995. doi: 10.1080/20013078.2019.1648995

Dutta, D., Williamson, C. D., Cole, N. B., and Donaldson, J. G. (2012). Pitstop 2 Is a potent inhibitor of clathrin-independent endocytosis. PLoS One 7:e45799. doi: 10.1371/journal.pone.0045799

Ebrahimi-Fakhari, D., Wahlster, L., Hoffmann, G. F., and Kölker, S. (2014). Emerging role of autophagy in pediatric neurodegenerative and neurometabolic diseases. Pediatric Res. 75, 217-226. doi: 10.1038/pr.2013.185

Eisele, Y. S., Monteiro, C., Fearns, C., Encalada, S. E., Wiseman, R. L., Powers, E. T., et al. (2015). Targeting protein aggregation for the treatment of degenerative diseases. Nat. Rev. Drug Discov. 14, 759-780. doi: 10.1038/ nrd4593

Ellinger, I., and Pietschmann, P. (2016). Endocytosis in health and diseasea thematic issue dedicated to Renate Fuchs. Wien. Med. Wochenschr. 166, 193-195. doi: 10.1007/s10354-016-0454-1

Emam, S. E., Ando, H., Lila, A. S. A., Shimizu, T., Okuhira, K., Ishima, Y., et al. (2018). Liposome co-incubation with cancer cells secreted exosomes (extracellular vesicles) with different proteins expressions and different uptake pathways. Sci. Rep. 8:14493.

Escrevente, C., Keller, S., Altevogt, P., and Costa, J. (2011). Interaction and uptake of exosomes by ovarian cancer cells. BMC Cancer 11:108. doi: 10.1186/14712407-11- 108

Evans, L. D., Wassmer, T., Fraser, G., Smith, J., Perkinton, M., Billinton, A., et al. (2018). Extracellular monomeric and aggregated tau efficiently enter human neurons through overlapping but distinct pathways. Cell Rep. 22, 3612-3624. doi: 10.1016/j.celrep.2018.03.021 
Fecto, F., Yan, J., Vemula, S. P., Liu, E., Yang, Y., Chen, W., et al. (2011). SQSTM1 mutations in familial and sporadic amyotrophic lateral sclerosis. Arch. Neurol. 68:1440. doi: 10.1001/archneurol.2011.250

Feng, D., Zhao, W. L., Ye, Y. Y., Bai, X. C., Liu, R. Q., Chang, L. F., et al. (2010). Cellular internalization of exosomes occurs through phagocytosis. Traffic 11, 675-687. doi: 10.1111/j.1600-0854.2010.01041.x

Feng, Y., He, D., Yao, Z., and Klionsky, D. J. (2014). The machinery of macroautophagy. Cell Res. 24, 24-41. doi: 10.1038/cr.2013.168

Fiandaca, M. S., Kapogiannis, D., Mapstone, M., Boxer, A., Eitan, E., Schwartz, J. B., et al. (2015). Identification of preclinical Alzheimer's disease by a profile of pathogenic proteins in neurally derived blood exosomes: a case-control study. Alzheimers Dement 11, e600-e607.

Fitzner, D., Schnaars, M., Van Rossum, D., Krishnamoorthy, G., Dibaj, P., Bakhti, M., et al. (2011). Selective transfer of exosomes from oligodendrocytes to microglia by macropinocytosis. J. Cell Sci. 124, 447-458. doi: 10.1242/jcs. 074088

Fred Dice, J. (1990). Peptide sequences that target cytosolic proteins for lysosomal proteolysis. Trends Biochem. Sci. 15, 305-309. doi: 10.1016/0968-0004(90) 90019-8

Fujiwara, M. E., and Zweifel, N. (2018). Courtemanche, and T.D. Pollard, Latrunculin A accelerates actin filament depolymerization in addition to sequestering actin monomers. Curr. Biol. 28, e3183-e3192.

Fujiwara, Y., Wada, K., and Kabuta, T. (2017). Lysosomal degradation of intracellular nucleic acids-multiple autophagic pathways. J. Biochem. 161, 145-154.

Fürthauer, M., and Smythe, E. (2014). Systems dynamics in endocytosis. Traffic 15, 338-346. doi: 10.1111/tra.12147

Gasser, O., Hess, C., Miot, S., Deon, C., Sanchez, J.-C., and Schifferli, J. ÜA. (2003). Characterisation and properties of ectosomes released by human polymorphonuclear neutrophils. Exp. Cell Res. 285, 243-257. doi: 10.1016/ s0014-4827(03)00055-7

Gaudin, Y., Ruigrok, R. H., Knossow, M., and Flamand, A. (1993). Low$\mathrm{pH}$ conformational changes of rabies virus glycoprotein and their role in membrane fusion. J. Virol. 67, 1365-1372. doi: 10.1128/jvi.67.3.1365-13 72.1993

Genschmer, K. R., Russell, D. W., Lal, C., Szul, T., Bratcher, P. E., Noerager, B. D., et al. (2019). Activated PMN exosomes: pathogenic entities causing matrix destruction and disease in the lung. Cell 176, e113-e126.

Gibbons, G. S., Banks, R. A., Kim, B., Xu, H., Changolkar, L., Leight, S. N., et al. (2017). GFP-Mutant Human Tau transgenic mice develop tauopathy following CNS Injections of Alzheimer's brain-derived pathological tau or synthetic mutant human tau fibrils. J. Neurosci. 37, 11485-11494. doi: 10.1523/jneurosci. 2393-17.2017

Goate, M.-C., Chartier-Harlin, M., Mullan, J., Brown, F., Crawford, L., Fidani, L., et al. (1991). Segregation of a missense mutation in the amyloid precursor protein gene with familial Alzheimer's disease. Nature 349, 704-706.

Goedert, M. (2015). Alzheimer's and Parkinson's diseases: the prion concept in relation to assembled $A \beta$, tau, and $\alpha$-synuclein. Science 349:1255555. doi: 10.1126/science. 1255555

Gonda, A., Kabagwira, J., Senthil, G. N., and Wall, N. R. (2019). Internalization of exosomes through receptor-mediated endocytosis. Mol. Cancer Res. 17, 337-347. doi: 10.1158/1541-7786.mcr-18-0891

Gribaudo, S., Tixador, P., Bousset, L., Fenyi, A., Lino, P., Melki, R., et al. (2019). Propagation of $\alpha$-Synuclein Strains within human reconstructed neuronal network. Stem Cell Rep. 12, 230-244. doi: 10.1016/j.stemcr.2018. 12.007

Grundke-Iqbal, I., Iqbal, K., Tung, Y. C., Quinlan, M., Wisniewski, H. M., and Binder, L. I. (1986). Abnormal phosphorylation of the microtubuleassociated protein tau (tau) in Alzheimer cytoskeletal pathology. Proc. Natl. Acad. Sci. U. S. A. 83, 4913-4917. doi: 10.1073/pnas.83. 13.4913

Guix, F. X., Corbett, G. T., Cha, D. J., Mustapic, M., Liu, W., Mengel, D., et al. (2018). Detection of aggregation-competent tau in neuron-derived extracellular vesicles. Int. J. Mol. Sci. 19:663. doi: 10.3390/ijms19030663

György, B., Szabó, T. G., Pásztói, M., Pál, Z., Misják, P., Aradi, B., et al. (2011). Membrane vesicles, current state-of-the-art: emerging role of extracellular vesicles. Cell. Mol. Life Sci. 68, 2667-2688. doi: 10.1007/s00018-0110689-3

Ha, K. D., Bidlingmaier, S. M., and Liu, B. (2016). Macropinocytosis exploitation by cancers and cancer therapeutics. Front. Physiol. 7:381. doi: 10.3389/fphys.2016. 00381

Haass, C., and Selkoe, D. J. (1993). Cellular processing of $\beta$-amyloid precursor protein and the genesis of amyloid $\beta$-peptide. Cell 75, 1039-1042. doi: 10.1016/ 0092-8674(93)90312-e

Hallinan, G. I., Vargas-Caballero, M., West, J., and Deinhardt, K. (2019). Tau misfolding efficiently propagates between individual intact hippocampal neurons. J. Neurosci. 39, 9623-9632. doi: 10.1523/jneurosci.159 $0-19.2019$

Hara, T., Nakamura, K., Matsui, M., Yamamoto, A., Nakahara, Y., SuzukiMigishima, R., et al. (2006). Suppression of basal autophagy in neural cells causes neurodegenerative disease in mice. Nature 441, 885-889. doi: 10.1038/ nature 04724

Harding, C., Heuser, J., and Stahl, P. (1983). Receptor-mediated endocytosis of transferrin and recycling of the transferrin receptor in rat reticulocytes. J. Cell Biol. 97, 329-339. doi: 10.1083/jcb.97.2.329

Harischandra, D. S., Rokad, D., Neal, M. L., Ghaisas, S., Manne, S., Sarkar, S., et al. (2019). Manganese promotes the aggregation and prion-like cell-to-cell exosomal transmission of $\alpha$-synuclein. Sci. Signal. 12:eaau4543. doi: 10.1126/ scisignal.aau4543

Harper, J. D., and Lansbury, P. T. Jr. (1997). Models of amyloid seeding in Alzheimer's disease and scrapie: mechanistic truths and physiological consequences of the time-dependent solubility of amyloid proteins. Annu. Rev. Biochem. 66, 385-407. doi: 10.1146/annurev.biochem. 66.1.385

Hassiotis, S., Manavis, J., Blumbergs, P. C., Hattersley, K. J., Carosi, J. M., Kamei, M., et al. (2018). Lysosomal LAMP1 immunoreactivity exists in both diffuse and neuritic amyloid plaques in the human hippocampus. Eur. J. Neurosci. 47, 1043-1053. doi: 10.1111/ejn.13913

Hazan-Halevy, I., Rosenblum, D., Weinstein, S., Bairey, O., Raanani, P., and Peer, D. (2015). Cell-specific uptake of mantle cell lymphoma-derived exosomes by malignant and non-malignant B-lymphocytes. Cancer Lett. 364, 59-69. doi: 10.1016/j.canlet.2015.04.026

He, C., and Klionsky, D. J. (2009). Regulation mechanisms and signaling pathways of autophagy. Annu. Rev. Genet. 43, 67-93. doi: 10.1146/annurev-genet102808-114910

Henderson, M. X., Cornblath, E. J., Darwich, A., Zhang, B., Brown, H., Gathagan, R. J., et al. (2019). Spread of $\alpha$-synuclein pathology through the brain connectome is modulated by selective vulnerability and predicted by network analysis. Nat. Neurosci. 22, 1248-1257. doi: 10.1038/s41593-01 9-0457-5

Heusermann, W., Hean, J., Trojer, D., Steib, E., Von Bueren, S., Graff-Meyer, A., et al. (2016). Exosomes surf on filopodia to enter cells at endocytic hot spots, traffic within endosomes, and are targeted to the ER. J. Cell Biol. 213, 173-184. doi: $10.1083 /$ jcb. 201506084

Hill, E., Van Der Kaay, J., Downes, C. P., and Smythe, E. (2001). The role of dynamin and its binding partners in coated pit invagination and scission. J. Cell Biol. 152, 309-324. doi: 10.1083/jcb.152.2.309

Hoffmann, A.-C., Minakaki, G., Menges, S., Salvi, R., Savitskiy, S., Kazman, A., et al. (2019). Extracellular aggregated alpha synuclein primarily triggers lysosomal dysfunction in neural cells prevented by trehalose. Sci. Rep. 9:544.

Hoffmann, P. R., Decathelineau, A. M., Ogden, C. A., Leverrier, Y., Bratton, D. L., Daleke, D. L., et al. (2001). Phosphatidylserine (PS) induces PS receptormediated macropinocytosis and promotes clearance of apoptotic cells. J. Cell Biol. 155, 649-660. doi: 10.1083/jcb.200108080

Holder, B., Jones, T., Sancho Shimizu, V., Rice, T. F., Donaldson, B., Bouqueau, M., et al. (2016). Macrophage exosomes induce placental inflammatory cytokines: a novel mode of maternal-placental messaging. Traffic 17, 168-178. doi: 10.1111/ tra. 12352

Horibe, S., Tanahashi, T., Kawauchi, S., Murakami, Y., and Rikitake, Y. (2018). Mechanism of recipient cell-dependent differences in exosome uptake. BMC Cancer 18:47. doi: 10.1186/s12885-017-3958-1

Hu, X., Crick, S. L., Bu, G., Frieden, C., Pappu, R. V., and Lee, J. M. (2009). Amyloid seeds formed by cellular uptake, concentration, and aggregation of 
the amyloid-beta peptide. Proc. Natl. Acad. Sci. U. S. A. 106, 20324-20329. doi: 10.1073/pnas.0911281106

Hussein, H. A. M., Walker, L. R., Abdel-Raouf, U. M., Desouky, S. A., Montasser, A. K. M., and Akula, S. M. (2015). Beyond RGD: virus interactions with integrins. Arch. Virol. 160, 2669-2681. doi: 10.1007/s00705-01 5-2579-8

Igami, K., Uchiumi, T., Ueda, S., Kamioka, K., Setoyama, D., Gotoh, K., et al. (2020). Characterization and function of medium and large extracellular vesicles from plasma and urine by surface antigens and Annexin V. PeerJ Anal. Chem. 2:e4. doi: 10.7717 /peerj-achem. 4

Ilahibaks, N. F., Lei, Z., Mol, E. A., Deshantri, A. K., Jiang, L., Schiffelers, R. M., et al. (2019). Biofabrication of cell-derived nanovesicles: a potential alternative to extracellular vesicles for regenerative medicine. Cells 8:1509. doi: 10.3390/ cells 8121509

Joseph, J. G., and Liu, A. P. (2020). Mechanical regulation of endocytosis: new insights and recent advances. Adv. Biosyst. 4:1900278. doi: 10.1002/adbi. 201900278

Joshi, B. S., De Beer, M. A., Giepmans, B. N., and Zuhorn, I. S. (2020). Endocytosis of extracellular vesicles and release of their cargo from endosomes. ACS Nano 4, 4444-4455. doi: 10.1021/acsnano.9b10033

Kaksonen, M., and Roux, A. (2018). Mechanisms of clathrin-mediated endocytosis. Nat. Rev. Mol. Cell Biol. 19, 313-326.

Karpowicz, R. J. Jr., Haney, C. M., Mihaila, T. S., Sandler, R. M., Petersson, E. J., and Lee, V. M. (2017). Selective imaging of internalized proteopathic $\alpha$-synuclein seeds in primary neurons reveals mechanistic insight into transmission of synucleinopathies. J. Biol. Chem. 292, 13482-13497. doi: 10.1074/jbc.m117. 780296

Kaufman, S. K., Del Tredici, K., Thomas, T. L., Braak, H., and Diamond, M. I. (2018). Tau seeding activity begins in the transentorhinal/entorhinal regions and anticipates phospho-tau pathology in Alzheimer's disease and PART. Acta Neuropathol. 136, 57-67. doi: 10.1007/s00401-018-1855-6

Kerr, M. C., and Teasdale, R. D. (2009). Defining macropinocytosis. Traffic 10, 364-371. doi: 10.1111/j.1600-0854.2009.00878.x

Kettler, K., Giannakou, C., De Jong, W. H., Hendriks, A. J., and Krystek, P. (2016). Uptake of silver nanoparticles by monocytic THP-1 cells depends on particle size and presence of serum proteins. J. Nanopart. Res. 18:286.

Kim, M., Sandford, E., Gatica, D., Qiu, Y., Liu, X., Zheng, Y., et al. (2016). Mutation in ATG5 reduces autophagy and leads to ataxia with developmental delay. eLife 5:e12245.

Kirchhausen, T. (2000). Clathrin. Annu. Rev. Biochem. 69, 699-727.

Koivusalo, M., Welch, C., Hayashi, H., Scott, C. C., Kim, M., Alexander, T., et al. (2010). Amiloride inhibits macropinocytosis by lowering submembranous $\mathrm{pH}$ and preventing Rac1 and Cdc42 signaling. J. Cell Biol. 188, 547-563. doi: $10.1083 /$ jcb. 200908086

Kooijmans, S. A. A., Schiffelers, R. M., Zarovni, N., and Vago, R. (2016). Modulation of tissue tropism and biological activity of exosomes and other extracellular vesicles: new nanotools for cancer treatment. Pharmacol. Res. 111, 487-500. doi: 10.1016/j.phrs.2016.07.006

Koumangoye, R. B., Sakwe, A. M., Goodwin, J. S., Patel, T., and Ochieng, J. (2011). Detachment of breast tumor cells induces rapid secretion of exosomes which subsequently mediate cellular adhesion and spreading. PLoS One 6:e24234. doi: 10.1371/journal.pone.0024234

Kovács, G. G., Gelpi, E., Ströbel, T., Ricken, G., Nyengaard, J. R., Bernheimer, H., et al. (2007). Involvement of the endosomal-lysosomal system correlates with regional pathology in creutzfeldt-jakob disease. J. Neuropathol. Exp. Neurol. 66, 628-636. doi: 10.1097/nen.0b013e318 093ecc7

Kruth, H. S., Jones, N. L., Huang, W., Zhao, B., Ishii, I., Chang, J., et al. (2005). Macropinocytosis is the endocytic pathway that mediates macrophage foam cell formation with native low density lipoprotein. J. Biol. Chem. 280, 2352-2360. doi: $10.1074 / j b c . m 407167200$

Kuhn, D. A., Vanhecke, D., Michen, B., Blank, F., Gehr, P., Petri-Fink, A., et al. (2014). Different endocytotic uptake mechanisms for nanoparticles in epithelial cells and macrophages. Beilstein J. Nanotechnol. 5, 1625-1636. doi: 10.3762/ bjnano.5.174

Kulkarni, R., Bajaj, M., Ghode, S., Jalnapurkar, S., Limaye, L., and Kale, V. P. (2018). Intercellular transfer of microvesicles from young mesenchymal stromal cells rejuvenates aged murine hematopoietic stem cells. Stem Cell. 36, 420-433. doi: $10.1002 /$ stem. 2756

Kwok, C. T., Morris, A., and de Belleroche, J. S. (2014). Sequestosome-1 (SQSTM1) sequence variants in ALS cases in the UK: prevalence and coexistence of SQSTM1 mutations in ALS kindred with PDB. Eur. J. Hum. Genet. 22, 492-496. doi: 10.1038/ejhg.2013.184

Lafon, M. (2005). Rabies virus receptors. J. Neurovirol. 11, 82-87. doi: 10.1080/ 13550280590900427

Lamark, T., and Johansen, T. (2012). Aggrephagy: selective disposal of protein aggregates by macroautophagy. Int. J. Cell Biol. 2012:736905.

Lamaze, C., Fujimoto, L. M., Yin, H. L., and Schmid, S. L. (1997). The actin cytoskeleton is required for receptor-mediated endocytosis in mammalian cells. J. Biol. Chem. 272, 20332-20335. doi: 10.1074/jbc.272.33.20332

Lawrence, R. E., and Zoncu, R. (2019). The lysosome as a cellular centre for signalling, metabolism and quality control. Nat. Cell Biol. 21, 133-142. doi: 10.1038/s41556-018-0244-7

Lee, H.-J., Khoshaghideh, F., Patel, S., and Lee, S.-J. (2004). Clearance of $\alpha$-Synuclein oligomeric intermediates via the lysosomal degradation pathway. J. Neurosci. 24, 1888-1896. doi: 10.1523/jneurosci.380903.2004

Lee, H.-J., Yoon, Y.-S., and Lee, S.-J. (2018). Mechanism of neuroprotection by trehalose: controversy surrounding autophagy induction. Cell Death Dis. 9:712.

Lentz, T., Burrage, T., Smith, A., Crick, J., and Tignor, G. (1982). Is the acetylcholine receptor a rabies virus receptor? Science 215, 182-184. doi: 10.1126/science. 7053569

Li, W.-W., Li, J., and Bao, J.-K. (2012). Microautophagy: lesser-known self-eating. Cell. Mol. Life Sci. 69, 1125-1136. doi: 10.1007/s00018-011-0865-5

Li, Y., Xu, M., Ding, X., Yan, C., Song, Z., Chen, L., et al. (2016). Protein kinase C controls lysosome biogenesis independently of mTORC1. Nat. Cell Biol. 18, 1065-1077. doi: $10.1038 / \mathrm{ncb} 3407$

Lim, J., and Yue, Z. (2015). Neuronal aggregates: formation, clearance, and spreading. Dev. Cell 32, 491-501. doi: 10.1016/j.devcel.2015.02.002

Lim, J. P., and Gleeson, P. A. (2011). Macropinocytosis: an endocytic pathway for internalising large gulps. Immunol. Cell Biol. 89, 836-843. doi: 10.1038/icb. 2011.20

Lin, H.-P., Singla, B., Ghoshal, P., Faulkner, J. L., Cherian-Shaw, M., O’Connor, P. M., et al. (2018). De Chantemele, and G. Csányi, Identification of novel macropinocytosis inhibitors using a rational screen of Food and Drug Administration-approved drugs. Br. J. Pharmacol. 175, 3640-3655. doi: 10. 1111/bph.14429

Lott, I. T., and Head, E. (2019). Dementia in Down syndrome: unique insights for Alzheimer disease research. Nat. Rev. Neurol. 15, 135-147. doi: 10.1038/ s41582-018-0132-6

Luan, X., Sansanaphongpricha, K., Myers, I., Chen, H., Yuan, H., and Sun, D. (2017). Engineering exosomes as refined biological nanoplatforms for drug delivery. Acta Pharmacol. Sinica 38, 754-763. doi: 10.1038/aps. 2017.12

Lucin, K. M., O’Brien, C. E., Bieri, G., Czirr, E., Mosher, K. I., Abbey, R. J., et al. (2013). Microglial Beclin 1 regulates retromer trafficking and phagocytosis and is impaired in Alzheimer's Disease. Neuron 79, 873-886. doi: 10.1016/j.neuron. 2013.06.046

Lwin, A., Orvisky, E., Goker-Alpan, O., LaMarca, M. E., and Sidransky, E. (2004). Glucocerebrosidase mutations in subjects with parkinsonism. Mol. Genet. Metab. 81, 70-73. doi: 10.1016/j.ymgme.2003.11.004

Macia, E., Ehrlich, M., Massol, R., Boucrot, E., Brunner, C., and Kirchhausen, T. (2006). Dynasore, a cell-permeable inhibitor of dynamin. Dev. Cell 10, 839-850. doi: 10.1016/j.devcel.2006.04.002

Malik, B. R., Maddison, D. C., Smith, G. A., and Peters, O. M. (2019). Autophagic and endo-lysosomal dysfunction in neurodegenerative disease. Mol. Brain $12: 100$.

Martinez-Vicente, M., Talloczy, Z., Kaushik, S., Massey, A. C., Mazzulli, J., Mosharov, E. V., et al. (2008). Dopamine-modified $\alpha$-synuclein blocks chaperone-mediated autophagy. J. Clin. Invest. 182, 777-788.

Martinez-Vicente, M., Talloczy, Z., Wong, E., Tang, G., Koga, H., Kaushik, S., et al. (2010). Cargo recognition failure is responsible for inefficient autophagy in Huntington's disease. Nat. Neurosci. 13, 567-576. doi: 10.1038/nn.2528 
Massey, A. C., Kaushik, S., Sovak, G., Kiffin, R., and Cuervo, A. M. (2006). Consequences of the selective blockage of chaperone-mediated autophagy. Proc. Natl. Acad. Sci. U. S. A. 103, 5805-5810. doi: 10.1073/pnas.0507436103

Masters, C. L., Multhaup, G., Simms, G., Pottgiesser, J., Martins, R. N., and Beyreuther, K. (1985). Neuronal origin of a cerebral amyloid: neurofibrillary tangles of Alzheimer's disease contain the same protein as the amyloid of plaque cores and blood vessels. EMBO J. 4, 2757-2763. doi: 10.1002/j.1460-2075.1985. tb04000.x

Mathieu, M., Martin-Jaular, L., Lavieu, G., and Thery, C. (2019). Specificities of secretion and uptake of exosomes and other extracellular vesicles for cell-to-cell communication. Nat. Cell Biol. 21, 9-17. doi: 10.1038/s41556-018-0250-9

Matsudaira, T., Mukai, K., Noguchi, T., Hasegawa, J., Hatta, T., Iemura, S.-I., et al. (2017). Endosomal phosphatidylserine is critical for the YAP signalling pathway in proliferating cells. Nat. Commun. 8:1246.

Mauthe, M., Orhon, I., Rocchi, C., Zhou, X., Luhr, M., Hijlkema, K. J., et al. (2018). Chloroquine inhibits autophagic flux by decreasing autophagosome-lysosome fusion. Autophagy 14, 1435-1455. doi: 10.1080/15548627.2018.1474314

Mauvezin, C., and Neufeld, T. P. (2015). Bafilomycin A1 disrupts autophagic flux by inhibiting both V-ATPase-dependent acidification and Ca-P60A/SERCAdependent autophagosome-lysosome fusion. Autophagy 11, 1437-1438. doi: 10.1080/15548627.2015.1066957

Mazulli, R. J., Xu, Y.-H., Sun, Y., Knight, A. L., McLean, P. J., Caldwell, G. A., et al. (2011). Gaucher Disease Glucocerebrosidase and $\alpha$-Synuclein form a bidirectional pathogenic loop in synucleinopathies. Cell 146, 37-52. doi: 10 . 1016/j.cell.2011.06.001

McGeachie, A. B., Odell, L. R., Quan, A., Daniel, J. A., Chau, N., Hill, T. A., et al. (2013). Pyrimidyn compounds: dual-action small molecule pyrimidine-based dynamin inhibitors. ACS Chem. Biol. 8, 1507-1518. doi: 10.1021/cb400137p

Mellman, I. (1996). Endocytosis and molecular sorting. Annu. Rev. Cell Dev. Biol. 12, 575-625. doi: 10.1146/annurev.cellbio.12.1.575

Menzies, F. M., Fleming, A., Caricasole, A., Bento, C. F., Andrews, S. P., Ashkenazi, A., et al. (2017). Autophagy and Neurodegeneration: pathogenic mechanisms and therapeutic opportunities. Neuron 93, 1015-1034. doi: 10.1016/j.neuron. 2017.01.022

Mercer, J., and Helenius, A. (2009). Virus entry by macropinocytosis. Nat. Cell Biol. 11, 510-520. doi: 10.1038/ncb0509-510

Mercer, J., Schelhaas, M., and Helenius, A. (2010). Virus entry by endocytosis. Annu. Rev. Biochem. 79, 803-833. doi: 10.1146/annurev-biochem-060208104626

Metaxakis, A., Ploumi, C., and Tavernarakis, N. (2018). Autophagy in ageassociated neurodegeneration. Cells 7:37. doi: 10.3390/cells7050037

Miaczynska, M., Pelkmans, L., and Zerial, M. (2004). Not just a sink: endosomes in control of signal transduction. Curr. Opin. Cell Biol. 16, 400-406. doi: 10.1016/j.ceb.2004.06.005

Miaczynska, M., and Stenmark, H. (2008). Mechanisms and functions of endocytosis: figure 1. J. Cell Biol. 180, 7-11. doi: 10.1083/jcb.200711073

Mijaljica, D., Prescott, M., and Devenish, R. J. (2011). Microautophagy in mammalian cells: revisiting a 40-year-old conundrum. Autophagy 7, 673-682. doi: 10.4161/auto.7.7.14733

Mindell, J. A. (2012). Lysosomal acidification mechanisms. Annu. Rev. Physiol. 74, 69-86. doi: 10.1146/annurev-physiol-012110-142317

Mizushima, N. (2018). A brief history of autophagy from cell biology to physiology and disease. Nat. Cell Biol. 20, 521-527. doi: 10.1038/s41556-0180092-5

Mizushima, N., and Komatsu, M. (2011). Autophagy: renovation of cells and tissues. Cell 147, 728-741. doi: 10.1016/j.cell.2011.10.026

Mizushima, N., Levine, B., Cuervo, A. M., and Klionsky, D. J. (2008). Autophagy fights disease through cellular self-digestion. Nature 451, 1069-1075. doi: 10. 1038/nature06639

Montecalvo, A. T., Larregina, W.J. Shufesky, Stolz, D. Beer, Sullivan, M. L. G., Karlsson, J. M., Baty, C. J., et al. (2012). Mechanism of transfer of functional microRNAs between mouse dendritic cells via exosomes. Blood 119, 756-766. doi: 10.1182/blood-2011-02-338004

Morelli, A. E., Larregina, A. T., Shufesky, W. J., Sullivan, M. L., Stolz, D. B., Papworth, G. D., et al. (2004). Endocytosis, intracellular sorting, and processing of exosomes by dendritic cells. Blood 104, 3257-3266. doi: 10.1182/blood-200403-0824
Mulcahy, L. A., Pink, R. C., and Carter, D. R. F. (2014). Routes and mechanisms of extracellular vesicle uptake. J. Extracell. Vesicles 3:24641. doi: 10.3402/jev.v3. 24641

Nakamura, S., and Yoshimori, T. (2017). New insights into autophagosomelysosome fusion. J. Cell Sci. 130, 1209-1216. doi: 10.1242/jcs.196352

Nakase, I., Kobayashi, N. B., Takatani-Nakase, T., and Yoshida, T. (2015). Active macropinocytosis induction by stimulation of epidermal growth factor receptor and oncogenic Ras expression potentiates cellular uptake efficacy of exosomes. Sci. Rep. 5:10300.

Nakase, I., Noguchi, K., Fujii, I., and Futaki, S. (2016). Vectorization of biomacromolecules into cells using extracellular vesicles with enhanced internalization induced by macropinocytosis. Sci. Rep. 6:34937.

Nalbandian, A., Llewellyn, K. J., Nguyen, C., Yazdi, P. G., and Kimonis, V. E. (2015). Rapamycin and Chloroquine: the In Vitro and In Vivo effects of autophagy-modifying drugs show promising results in valosin containing protein multisystem proteinopathy. PLoS One 10:e0122888. doi: 10.1371/ journal.pone.0122888

Nanbo, A., Kawanishi, E., Yoshida, R., and Yoshiyama, H. (2013). Exosomes derived from epstein-barr virus-infected cells are internalized via caveoladependent endocytosis and promote phenotypic modulation in target cells. J. Virol. 87, 10334-10347. doi: 10.1128/jvi.01310-13

Narasimhan, S., Guo, J. L., Changolkar, L., Stieber, A., McBride, J. D., Silva, L. V., et al. (2017). Pathological Tau strains from human brains recapitulate the diversity of tauopathies in nontransgenic mouse brain. J. Neurosci. 37, 11406-11423. doi: 10.1523/jneurosci.1230-17.2017

Neumann, M., Sampathu, D. M., Kwong, L. K., Truax, A. C., Micsenyi, M. C., Chou, T. T., et al. (2006). Ubiquitinated TDP-43 in frontotemporal lobar degeneration and amyotrophic lateral sclerosis. Science 314, 130-133.

Nilsson, P., Loganathan, K., Sekiguchi, M., Matsuba, Y., Hui, K., Tsubuki, S., et al. (2013). A $\beta$ secretion and plaque formation depend on autophagy. Cell Rep. 5, 61-69. doi: 10.1016/j.celrep.2013.08.042

Nixon, R. A., Wegiel, J., Kumar, A., Yu, W. H., Peterhoff, C., Cataldo, A., et al. (2005). Extensive involvement of autophagy in Alzheimer disease: an immunoelectron microscopy study. J. Neuropathol. Exp. Neurol. 64, 113-122. doi: $10.1093 /$ jnen/64.2.113

Nolte-'T Hoen, E. N. M., Buschow, S. I., Anderton, S. M., Stoorvogel, W., and Wauben, M. H. M. (2009). Activated T cells recruit exosomes secreted by dendritic cells via LFA-1. Blood 113, 1977-1981. doi: 10.1182/blood-2008-08174094

O’Brien, K., Breyne, K., Ughetto, S., Laurent, L. C., and Breakefield, X. O. (2020). RNA delivery by extracellular vesicles in mammalian cells and its applications. Nat. Rev. Mol. Cell Biol. 21, 585-606. doi: 10.1038/s41580-020-0251-y

Ochaba, J., Lukacsovich, T., Csikos, G., Zheng, S., Margulis, J., Salazar, L., et al. (2014). Potential function for the Huntingtin protein as a scaffold for selective autophagy. Proc. Natl. Acad. Sci. U. S. A. 111, 16889-16894. doi: 10.1073/pnas. 1420103111

Odagiri, S., Tanji, K., Mori, F., Kakita, A., Takahashi, H., and Wakabayashi, K. (2012). Autophagic adapter protein NBR1 is localized in Lewy bodies and glial cytoplasmic inclusions and is involved in aggregate formation in $\alpha$ synucleinopathy. Acta Neuropathol. 124, 173-186. doi: 10.1007/s00401-0120975-7

Ogese, M. O., Jenkins, R. E., Adair, K., Tailor, A., Meng, X., Faulkner, L., et al. (2019). Exosomal transport of hepatocyte-derived drug-modified proteins to the immune system. Hepatology 70, 1732-1749. doi: 10.1002/hep. 30701

Oh, P., McIntosh, D. P., and Schnitzer, J. E. (1998). Dynamin at the neck of caveolae mediates their budding to form transport vesicles by GTP-driven fission from the plasma membrane of endothelium. J. Cell Biol. 141, 101-114. doi: $10.1083 /$ jcb.141.1.101

Orenstein, S. J., and Cuervo, A. M. (2010). Chaperone-mediated autophagy: molecular mechanisms and physiological relevance. Semin. Cell Dev. Biol. 21, 719-726. doi: 10.1016/j.semcdb.2010.02.005

Osawa, T., Mizuno, Y., Fujita, Y., Takatama, M., Nakazato, Y., and Okamoto, K. (2011). Optineurin in neurodegenerative diseases. Neuropathology 31, 569-574. doi: 10.1111/j.1440-1789.2011.01199.x

Osellame, L. D., Rahim, A. A., Hargreaves, I. P., Gegg, M. E., Richard-Londt, A., Brandner, S., et al. (2013). Mitochondria and quality control defects in a 
mouse model of gaucher disease-links to Parkinson's Disease. Cell Metab. 17, 941-953. doi: 10.1016/j.cmet.2013.04.014

Øverbye, M. F. (2007). Brinchmann, and P.O. seglen, proteomic analysis of membrane-associated proteins from rat liver autophagosomes. Autophagy 3, 300-322. doi: 10.4161/auto.3910

Pan, B. T. (1985). Electron microscopic evidence for externalization of the transferrin receptor in vesicular form in sheep reticulocytes. J. Cell Biol. 101, 942-948. doi: 10.1083/jcb.101.3.942

Pan, B.-T., and Johnstone, R. M. (1983). Fate of the transferrin receptor during maturation of sheep reticulocytes in Vitro: selective externalization of the receptor. Cell 33, 967-978. doi: 10.1016/0092-8674(83) 90040-5

Pan, K. M., Baldwin, M., Nguyen, J., Gasset, M., Serban, A., Groth, D., et al. (1993). Conversion of alpha-helices into beta-sheets features in the formation of the scrapie prion proteins. Proc. Natl. Acad. Sci. U. S. A. 90, 10962-10966. doi: 10.1073 /pnas.90.23.10962

Pan, Q., Ramakrishnaiah, V., Henry, S., Fouraschen, S., De Ruiter, P. E., Kwekkeboom, J., et al. (2012). Hepatic cell-to-cell transmission of small silencing RNA can extend the therapeutic reach of RNA interference (RNAi). Gut 61, 1330-1339. doi: 10.1136/gutjnl-2011-30 0449

Pandey, U. B., Nie, Z., Batlevi, Y., McCray, B. A., Ritson, G. P., Nedelsky, N. B., et al. (2007). HDAC6 rescues neurodegeneration and provides an essential link between autophagy and the UPS. Nature 447, 859-863.

Pankiv, S., Clausen, T. H., Lamark, T., Brech, A., Bruun, J.-A., Outzen, H., et al. (2007). p62/SQSTM1 Binds Directly to Atg8/LC3 to facilitate degradation of ubiquitinated protein aggregates by autophagy. J. Biol. Chem. 282, 2413124145. doi: $10.1074 /$ jbc.m702824200

Parolini, I., Federici, C., Raggi, C., Lugini, L., Palleschi, S., Milito, A. De, et al. (2009). Microenvironmental pH Is a key factor for exosome traffic in tumor cells. J. Biol. Chem. 284, 34211-34222. doi: 10.1074/jbc.m109. 041152

Parton, R. G., and Collins, B. M. (2016). Unraveling the architecture of caveolae. Proc. Natl. Acad. Sci. U. S. A. 113, 14170-14172. doi: 10.1073/pnas.161795 4113

Pasternak, S. H., Callahan, J. W., and Mahuran, D. J. (2004). The role of the endosomal/lysosomal system in amyloid-beta production and the pathophysiology of Alzheimer's disease: reexamining the spatial paradox from a lysosomal perspective. J. Alzheimers Dis. 6, 53-65. doi: 10.3233/jad-20 04-6107

Pedrioli, G., Barberis, M., Molinari, M., Morone, D., Papin, S., and Paganetti, P. (2020). Extracellular vesicles hijack the autophagic pathway to induce tau accumulation in endolysosomes. bioRxiv [preprint] doi: 10.1101/2020.05.27. 118323

Pfrieger, F. W., and Vitale, N. (2018). Cholesterol and the journey of extracellular vesicles. J. Lipid Res. 59, 2255-2261. doi: 10.1194/jlr.r08 4210

Pickford, F., Masliah, E., Britschgi, M., Lucin, K., Narasimhan, R., Jaeger, P. A., et al. (2008). The autophagy-related protein beclin 1 shows reduced expression in early Alzheimer disease and regulates amyloid $\beta$ accumulation in mice. J. Clin. Invest. 118, 2190-2199.

Piras, A., Collin, L., Grüninger, F., Graff, C., and Rönnbäck, A. (2016). Autophagic and lysosomal defects in human tauopathies: analysis of post-mortem brain from patients with familial Alzheimer disease, corticobasal degeneration and progressive supranuclear palsy. Acta Neuropathol. Commun. 4:22.

Polanco, J. C., Li, C., Durisic, N., Sullivan, R., and Götz, J. (2018). Exosomes taken up by neurons hijack the endosomal pathway to spread to interconnected neurons. Acta Neuropathol. Commun. $6: 10$

Polymeropoulos, M. H., Lavedan, C., Leroy, E., Ide, S. E., Dehejia, A., Dutra, A., et al. (1997). Mutation in the a-synuclein gene identified in families with Parkinson's disease. Science 276, 2045-2047. doi: 10.1126/science.276.5321. 2045

Poulson, B. G., Szczepski, K., Lachowicz, J. I., Jaremko, L., Emwas, A.H., and Jaremko, M. (2020). Aggregation of biologically important peptides and proteins: inhibition or acceleration depending on protein and metal ion concentrations. RSC $A d v$. 10, 215-227. doi: 10.1039/c9ra 09350h
Prada, I., and Meldolesi, J. (2016). Binding and fusion of extracellular vesicles to the plasma membrane of their cell targets. Int. J. Mol. Sci. 17:1296. doi: 10.3390/ijms 17081296

Ramesh Babu, J., Lamar Seibenhener, M., Peng, J., Strom, A. L., Kemppainen, R., Cox, N., et al. (2008). Genetic inactivation of p62 leads to accumulation of hyperphosphorylated tau and neurodegeneration. J. Neurochem. 106, 107-120. doi: 10.1111/j.1471-4159.2008.05340.x

Raposo, G., Nijman, H. W., Stoorvogel, W., Liejendekker, R., Harding, C. V., Melief, C. J., et al. (1996). B lymphocytes secrete antigen-presenting vesicles. J. Exp. Med. 183, 1161-1172. doi: 10.1084/jem.183.3.1161

Raposo, G., and Stoorvogel, W. (2013). Extracellular vesicles: exosomes, microvesicles, and friends. J. Cell Biol. 200, 373-383. doi: 10.1083/jcb. 201211138

Rappa, G., Santos, M. F., Green, T. M., Karbanová, J., Hassler, J., Bai, Y., et al. (2017). Nuclear transport of cancer extracellular vesiclederived biomaterials through nuclear envelope invagination-associated late endosomes. Oncotarget 8, 14443-14461. doi: 10.18632/oncotarget. 14804

Ravikumar, B., Duden, R., and Rubinsztein, D. C. (2002). Aggregate-prone proteins with polyglutamine and polyalanine expansions are degraded by autophagy. Hum. Mol. Genet. 11, 1107-1117. doi: 10.1093/hmg/11.9.1107

Ravikumar, B., Vacher, C., Berger, Z., Davies, J. E., Luo, S., Oroz, L. G., et al. (2004). Inhibition of mTOR induces autophagy and reduces toxicity of polyglutamine expansions in fly and mouse models of Huntington disease. Nat. Genet. 36, 585-595. doi: $10.1038 /$ ng 1362

Richards, D. M., and Endres, R. G. (2014). The mechanism of phagocytosis: two stages of engulfment. Biophys. J. 107, 1542-1553. doi: 10.1016/j.bpj.2014.07.070

Ridder, K., Keller, S., Dams, M., Rupp, A.-K., Schlaudraff, J., Del Turco, D., et al. (2014). Extracellular vesicle-mediated transfer of genetic information between the hematopoietic system and the brain in response to inflammation. PLoS Biol. 12:e1001874. doi: 10.1371/journal.pbio.1001874

Ridder, K., Sevko, A., Heide, J., Dams, M., Rupp, A.-K., Macas, J., et al. (2015). Extracellular vesicle-mediated transfer of functional RNA in the tumor microenvironment. OncoImmunology 4:e1008371. doi: 10.1080/2162402x. 2015.1008371

Rosales, C., and Uribe-Querol, E. (2017). Phagocytosis: a fundamental process in immunity. BioMed Res. Int. 2017:9042851.

Ross, C. A., and Poirier, M. A. (2005). Opinion: what is the role of protein aggregation in neurodegeneration? Nat. Rev. Mol. Cell Biol. 6, 891-898. doi: $10.1038 / \mathrm{nrm} 1742$

Rubartelli, A., Poggi, A., and Zocchi, M. R. (1997). The selective engulfment of apoptotic bodies by dendritic cells is mediated by the $\alpha v \beta 3$ integrin and requires intracellular and extracellular calcium. Eur. J. Immunol. 27, 1893-1900. doi: 10.1002/eji.1830270812

Sahu, R., Kaushik, S., Clement, C. C., Cannizzo, E. S., Scharf, B., Follenzi, A., et al. (2011). Microautophagy of cytosolic proteins by late endosomes. Dev. Cell 20, 131-139. doi: 10.1016/j.devcel.2010.12.003

Sallusto, F. (1995). Dendritic cells use macropinocytosis and the mannose receptor to concentrate macromolecules in the major histocompatibility complex class II compartment: downregulation by cytokines and bacterial products. J. Exp. Med. 182, 389-400. doi: 10.1084/jem.182.2.389

Sarkar, S., Davies, J. E., Huang, Z., Tunnacliffe, A., and Rubinsztein, D. C. (2007) Trehalose, a Novel mTOR-independent autophagy enhancer, accelerates the clearance of mutant huntingtin and $\alpha$-synuclein. J. Biol. Chem. 282, 5641-5652. doi: 10.1074/jbc.m609532200

Savina, A., and Amigorena, S. (2007). Phagocytosis and antigen presentation in dendritic cells. Immunol. Rev. 219, 143-156. doi: 10.1111/j.1600-065x.2007. 00552.x

Savolainen, M. H., Richie, C. T., Harvey, B. K., Männistö, P. T., MaguireZeiss, K. A., and Myöhänen, T. T. (2014). The beneficial effect of a prolyl oligopeptidase inhibitor, KYP-2047, on alpha-synuclein clearance and autophagy in A30P transgenic mouse. Neurobiol. Dis. 68, 1-15. doi: 10.1016/ j.nbd.2014.04.003

Sever, S., Damke, H., and Schmid, S. L. (2000). Dynamin:Gtp controls the formation of constricted coated pits, the rate limiting step in clathrin-mediated endocytosis. J. Cell Biol. 150, 1137-1148. doi: 10.1083/jcb.150.5.1137

Shahmoradian, S. H., Lewis, A. J., Genoud, C., Hench, J., Moors, T. E., Navarro, P. P., et al. (2019). Lewy pathology in Parkinson's disease consists of crowded 
organelles and lipid membranes. Nat. Neurosci. 22, 1099-1109. doi: 10.1038/ s41593-019-0423-2

Shaid, S., Brandts, C. H., Serve, H., and Dikic, I. (2013). Ubiquitination and selective autophagy. Cell Death Dif. 20, 21-30. doi: 10.1038/cdd.2012.72

Shayakhmetov, D. M., Eberly, A. M., Li, Z. Y., and Lieber, A. (2005). Deletion of Penton RGD motifs affects the efficiency of both the internalization and the endosome escape of viral particles containing adenovirus serotype 5 or 35 Fiber Knobs. J. Virol. 79, 1053-1061. doi: 10.1128/jvi.79.2.1053-10 61.2005

Shelke, G. V., Yin, Y., Jang, S. C., Lässer, C., Wennmalm, S., Hoffmann, H. J., et al. (2019). Endosomal signalling via exosome surface TGF $\beta$-1. J. Extracell. Vesicles 8:1650458. doi: 10.1080/20013078.2019.1650458

Shen, W.-C., Li, H.-Y., Chen, G.-C., Chern, Y., and Tu, P.-H. (2015). Mutations in the ubiquitin-binding domain of OPTN/optineurin interfere with autophagy-mediated degradation of misfolded proteins by a dominant-negative mechanism. Autophagy 11, 685-700. doi: 10.4161/auto.36098

Shibata, M., Lu, T., Furuya, T., Degterev, A., Mizushima, N., Yoshimori, T., et al. (2006). Regulation of intracellular accumulation of mutant huntingtin by beclin 1. J. Biol. Chem. 281, 14474-14485. doi: 10.1074/jbc.m600 364200

Shim, S. Y., Karri, S., Law, S., Schatzl, H. M., and Gilch, S. (2016). Prion infection impairs lysosomal degradation capacity by interfering with rab7 membrane attachment in neuronal cells. Sci. Rep. 6:21658.

Sikorska, B., Liberski, P. P., Giraud, P., Kopp, N., and Brown, P. (2004). Autophagy is a part of ultrastructural synaptic pathology in Creutzfeldt-Jakob disease: a brain biopsy study. Int. J. Biochem. Cell Biol. 36, 2563-2573. doi: 10.1016/j. biocel.2004.04.014

Singleton, A. B., Farrer, M., Johnson, J., Singleton, A., Hague, S., Kachergus, J., et al. (2003). alpha-Synuclein locus triplication causes Parkinson's disease. Science 302:841. doi: $10.1126 /$ science. 1090278

Skog, J., Wurdinger, T., van Rijn, S., Meijer, D. H., Gainche, L., Sena-Esteves, M., et al. (2008). Glioblastoma microvesicles transport RNA and proteins that promote tumour growth and provide diagnostic biomarkers. Nat. Cell Biol. 10, 1470-1476. doi: 10.1038/ncb1800

Skotland, T., Sagini, K., Sandvig, K., and Llorente, A. (2020). An emerging focus on lipids in extracellular vesicles. Adv. Drug Deliv. Rev. S0169-409X, 30014-30014.

Song, M., Wang, Y., Shang, Z.-F., Liu, X.-D., Xie, D.-F., Wang, Q., et al. (2016). Bystander autophagy mediated by radiation-induced exosomal miR-7-5p in non-targeted human bronchial epithelial cells. Sci. Rep. 6: 30165.

Soto, C., and Pritzkow, S. (2018). Protein misfolding, aggregation, and conformational strains in neurodegenerative diseases. Nat. Neurosci. 21, 13321340. doi: 10.1038/s41593-018-0235-9

Spencer, B., Potkar, R., Trejo, M., Rockenstein, E., Patrick, C., Gindi, R., et al. (2009). Beclin 1 Gene Transfer activates autophagy and ameliorates the neurodegenerative pathology in a-synuclein models of parkinson's and lewy body diseases. J. Neurosci. 29, 13578-13588. doi: 10.1523/jneurosci.4390-09. 2009

Spilman, P., Podlutskaya, N., Hart, M. J., Debnath, J., Gorostiza, O., Bredesen, D., et al. (2010). Inhibition of mTOR by rapamycin abolishes cognitive deficits and reduces Amyloid- $\beta$ levels in a mouse model of alzheimer's disease. PLoS One 5:e9979. doi: 10.1371/journal.pone.0009979

Srivastava, K. R., and Lapidus, L. J. (2017). Prion protein dynamics before aggregation. Proc. Natl. Acad. Sci. U. S. A. 114, 3572-3577. doi: 10.1073/pnas. 1620400114

Staring, J., Raaben, M., and Brummelkamp, T. R. (2018). Viral escape from endosomes and host detection at a glance. J. Cell Sci. 131:jcs216259. doi: $10.1242 /$ jcs. 216259

Steele, J. W., Lachenmayer, M. L., Ju, S., Stock, A., Liken, J., Kim, S. H., et al. (2013). Latrepirdine improves cognition and arrests progression of neuropathology in an Alzheimer's mouse model. Mol. Psychiatry 18, 889-897. doi: 10.1038/mp. 2012.106

Steenbeek, S. C., Pham, T. V., Ligt, J., Zomer, A., Knol, J. C., Piersma, S. R., et al. (2018). Cancer cells copy migratory behavior and exchange signaling networks via extracellular vesicles. EMBO J. 37:e98357.

Steinman, R. M. (1983). Endocytosis and the recycling of plasma membrane. J. Cell Biol. 96, 1-27.
Sterzenbach, U., Putz, U., Low, L.-H., Silke, J., Tan, S.-S., and Howitt, J. (2017). Engineered exosomes as vehicles for biologically active proteins. Mol. Ther. 25, 1269-1278. doi: 10.1016/j.ymthe.2017.03.030

Stolz, A. (2014). Ernst, and I. Dikic, Cargo recognition and trafficking in selective autophagy. Nat. Cell Biol. 16, 495-501. doi: 10.1038/ncb2979

Stuart, L. M., and Ezekowitz, R. A. B. (2005). Phagocytosis. Immunity 22, 539-550. Sullivan, A. L., Grasso, J. A., and Weintraub, L. R. (1976). Micropinocytosis of transferrin by developing red cells: an electron-microscopic study utilizing ferritin-conjugated transferrin and ferritin-conjugated antibodies to transferrin. Blood 47, 133-143. doi: 10.1182/blood.v47.1.133. bloodjournal471133

Svensson, K. J., Christianson, H. C., Wittrup, A., Bourseau-Guilmain, E., Lindqvist, E., Svensson, L. M., et al. (2013). Exosome Uptake Depends on ERK1/2heat shock protein 27 signaling and lipid raft-mediated endocytosis negatively regulated by Caveolin-1. J. Biol. Chem. 288, 17713-17724. doi: 10.1074/jbc. m112.445403

Swanson, J. A. (2008). Shaping cups into phagosomes and macropinosomes. Nat. Rev. Mol. Cell Biol. 9, 639-649. doi: 10.1038/nrm2447

Swanson, J. A., and Watts, C. (1995). Macropinocytosis. Trends Cell Biol. 5, 424-428.

Taelman, V. F., Dobrowolski, R., Plouhinec, J. L., Fuentealba, L. C., Vorwald, P. P., Gumper, I., et al. (2010). Wnt signaling requires sequestration of glycogen synthase kinase 3 inside multivesicular endosomes. Cell 143, 1136-1148. doi: 10.1016/j.cell.2010.11.034

Tanaka, M., Machida, Y., Niu, S., Ikeda, T., Jana, N. R., Doi, H., et al. (2004). Trehalose alleviates polyglutamine-mediated pathology in a mouse model of Huntington disease. Nat. Med. 10, 148-154. doi: 10.1038/ nm985

Tanida, I. (2011). Autophagosome formation and molecular mechanism of autophagy. Antioxid. Redox Signal. 14, 2201-2214. doi: 10.1089/ars.2010.3482

Terry, R. D. (1963). The fine sctructure of neurofibrillary tangles in Alzheimer's disease. J. Neuropathol. Exp. Neurol. 22, 629-642.

Théry, C., Boussac, M., Véron, P., Ricciardi-Castagnoli, P., Raposo, G., Garin, J., et al. (2001). Proteomic analysis of dendritic cell-derived exosomes: a secreted subcellular compartment distinct from apoptotic vesicles. J. Immunol. 166, 7309-7318. doi: 10.4049/jimmunol.166. 12.7309

Théry, C., Regnault, A., Garin, J., Wolfers, J., Zitvogel, L., Ricciardi-Castagnoli, P., et al. (1999). Molecular characterization of dendritic cell-derived exosomes. J. Cell Biol. 147, 599-610. doi: 10.1083/jcb.147.3.599

Thompson, A. G., Gray, E., Heman-Ackah, S. M., Mäger, I., Talbot, K., Andaloussi, S. E., et al. (2016). Extracellular vesicles in neurodegenerative disease pathogenesis to biomarkers. Nat. Rev. Neurol. 12, 346-357. doi: 10.1038/ nrneurol.2016.68

Tian, T., Zhu, Y.-L., Zhou, Y.-Y., Liang, G.-F., Wang, Y.-Y., Hu, F.-H., et al. (2014a). Exosome Uptake through Clathrin-mediated endocytosis and macropinocytosis and mediating miR-21 delivery. J. Biol. Chem. 289:2225822267. doi: $10.1074 /$ jbc.m114.588046

Tian, Y., Li, S., Song, J., Ji, T., Zhu, M., Anderson, G. J., et al. (2014b). delivery platform using engineered natural membrane vesicle exosomes for targeted tumor therapy. Biomaterials 35, 2383-2390. doi: 10.1016/j.biomaterials.2013. 11.083

Tooze, S. A., and Yoshimori, T. (2010). The origin of the autophagosomal membrane. Nat. Cell Biol. 12, 831-835. doi: 10.1038/ncb0910-831

Tsujimura, A., Taguchi, K., Watanabe, Y., Tatebe, H., Tokuda, T., Mizuno, T., et al. (2015). Lysosomal enzyme cathepsin B enhances the aggregate forming activity of exogenous $\alpha$-synuclein fibrils. Neurobiol. Dis. 73, 244-253. doi: 10.1016/j.nbd.2014.10.011

Uversky, V. N. (2007). Neuropathology, biochemistry, and biophysics of ?synuclein aggregation. J. Neurochem. 130, 17-37.

Valadi, H., Ekström, K., Bossios, A., Sjöstrand, M., Lee, J. J., and Lötvall, J. O. (2007). Exosome-mediated transfer of mRNAs and microRNAs is a novel mechanism of genetic exchange between cells. Nat. Cell Biol. 9, 654-659. doi: 10.1038/ ncb1596

Valionyte, E., Yang, Y., Roberts, S. L., Kelly, J., Lu, B., and Luo, S. (2020). Lowering mutant huntingtin levels and Toxicity: autophagy-endolysosome pathways in huntington's disease. J. Mol. Biol. 432, 2673-2691. doi: 10.1016/j.jmb.2019. 11.012 
Van Dongen, H. M., Masoumi, N., Witwer, K. W., and Pegtel, D. M. (2016). Extracellular vesicles exploit viral entry routes for cargo delivery. Microbiol. Mol. Biol. Rev. 80, 369-386. doi: 10.1128/mmbr.00063-15

van Niel, G., Charrin, S., Simoes, S., Romao, M., Rochin, L., Saftig, P., et al. (2011). The Tetraspanin CD63 Regulates ESCRT-independent and -dependent endosomal sorting during Melanogenesis. Dev. Cell 21, 708-721. doi: 10.1016/ j.devcel.2011.08.019

van Niel, G., D’Angelo, G., and Raposo, G. (2018). Shedding light on the cell biology of extracellular vesicles. Nat. Rev. Mol. Cell Biol. 19, 213-228. doi: 10.1038/nrm.2017.125

Vella, L., Sharples, R., Lawson, V., Masters, C., Cappai, R., and Hill, A. (2007). Packaging of prions into exosomes is associated with a novel pathway of PrP processing. J. Pathol. 211, 582-590. doi: 10.1002/path.2145

Veltman, D. M., Williams, T. D., Bloomfield, G., Chen, B.-C., Betzig, E., Insall, R. H., et al. (2016). A plasma membrane template for macropinocytic cups. Elife 5:e20085.

Verweij, F. J., Revenu, C., Arras, G., Dingli, F., Loew, D., Pegtel, D. M., et al. (2019). Live tracking of inter-organ communication by endogenous exosomes in vivo. Dev. Cell 48, e573-e589.

von Kleist, L., Stahlschmidt, W., Bulut, H., Gromova, K., Puchkov, D., and Robertson, M. J. (2011). Role of the clathrin terminal domain in regulating coated pit dynamics revealed by small molecule inhibition. Cell 146, 471-484. doi: 10.1016/j.cell.2011.06.025

Wang, B., Xing, D., Zhu, Y., Dong, S., and Zhao, B. (2019). The state of exosomes research: a global visualized analysis. BioMed Res. Int. 2019:1495130.

Wang, L. H., Rothberg, K. G., and Anderson, R. G. (1993). Mis-assembly of clathrin lattices on endosomes reveals a regulatory switch for coated pit formation. J. Cell Biol. 123, 1107-1117. doi: 10.1083/jcb.123.5.1107

Wang, Z., Tiruppathi, C., Minshall, R. D., and Malik, A. B. (2009). Size and dynamics of caveolae studied using nanoparticles in living endothelial cells. ACS Nano 3, 4110-4116. doi: 10.1021/nn9012274

Watson, L. S., Hamlett, E. D., Stone, T. D., and Sims-Robinson, C. (2019). Neuronally derived extracellular vesicles: an emerging tool for understanding Alzheimer's disease. Mol. Neurodegener. 14:22.

Wegmann, S., Bennett, R. E., Delorme, L., Robbins, A. B., Hu, M., MacKenzie, D., et al. (2019). Experimental evidence for the age dependence of tau protein spread in the brain. Sci. Adv. 5:eaaw6404. doi: 10.1126/sciadv.aaw6404

Wesselborg, S., and Stork, B. (2015). Autophagy signal transduction by ATG proteins: from hierarchies to networks. Cell. Mol. Life Sci. 72, 4721-4757. doi: 10.1007/s00018-015-2034-8

Williams, C., Pazos, R., Royo, F., González, E., Roura-Ferrer, M., Martinez, A., et al. (2019). Assessing the role of surface glycans of extracellular vesicles on cellular uptake. Sci. Rep. 9:11920.

Williams, C., Royo, F., Aizpurua-Olaizola, O., Pazos, R., Boons, G.-J., Reichardt, N.-C., et al. (2018). Glycosylation of extracellular vesicles: current knowledge, tools and clinical perspectives. J. Extracell. Vesicles 7:1442985. doi: 10.1080/ 20013078.2018.1442985

Willox, A. K., Sahraoui, Y. M. E., and Royle, S. J. (2014). Non-specificity of Pitstop 2 in clathrin-mediated endocytosis. Biol. Open 3, 326-331. doi: 10.1242/bio. 20147955

Winchester, B. (2005). Lysosomal metabolism of glycoproteins. Glycobiology 15, $1 \mathrm{R}-15 \mathrm{R}$.

Wong, E., and Cuervo, A. M. (2010). Autophagy gone awry in neurodegenerative diseases. Nat. Neurosci. 13, 805-811. doi: 10.1038/nn.2575
Xie, Z., and Klionsky, D. J. (2007). Autophagosome formation: core machinery and adaptations. Nat. Cell Biol. 9, 1102-1109. doi: 10.1038/ncb1007-1102

Xiong, J. (2015). Atg7 in development and disease: panacea or Pandora's Box? Protein Cell 6, 722-734. doi: 10.1007/s13238-015-0195-8

Yamamoto, A., Tagawa, Y., Yoshimori, T., Moriyama, Y., Masaki, R., and Tashiro, Y. (1998). Bafilomycin A1 prevents maturation of autophagic vacuoles by inhibiting fusion between autophagosomes and lysosomes in rat hepatoma cell line, H-4-II-E cells. Cell Struct. Funct. 23, 33-42. doi: 10.1247/csf.23.33

Yang, D.-S., Stavrides, P., Mohan, P. S., Kaushik, S., Kumar, A., Ohno, M., et al. (2011). Reversal of autophagy dysfunction in the TgCRND8 mouse model of Alzheimer's disease ameliorates amyloid pathologies and memory deficits. Brain 134, 258-277. doi: 10.1093/brain/awq341

Yang, S.-T., Kreutzberger, A. J. B., Lee, J., Kiessling, V., and Tamm, L. K. (2016). The role of cholesterol in membrane fusion. Chem. Phys. Lipids 199, 136-143. doi: 10.1016/j.chemphyslip.2016.05.003

Yang, Y., Hong, Y., Cho, E., Kim, G. B., and Kim, I.-S. (2018). Extracellular vesicles as a platform for membrane-associated therapeutic protein delivery. J. Extracell. Vesicles 7:1440131. doi: 10.1080/20013078.2018.1440131

Yao, Z., Qiao, Y., Li, X., Chen, J., Ding, J., Bai, L., et al. (2018). Exosomes exploit the virus entry machinery and pathway to transmit alpha interferon-induced antiviral activity. J. Virol. 92, e1578-e1518.

Yarmola, E. G., Somasundaram, T., Boring, T. A., Spector, I., and Bubb, M. R. (2000). Actin-latrunculin A structure and function:differential modulation of actin-binding protein function by latrunculin A. J. Biol. Chem. 275, 2812028127.

Yoon, Y.-S., Cho, E.-D., Ahn, W. J., Lee, K. W., Lee, S.-J., and Lee, H.-J. (2017). Is trehalose an autophagic inducer? Unraveling theroles of non-reducing disaccharides on autophagic fluxand alpha-synuclein aggregation. Cell Death Dis. 8:e3091. doi: 10.1038/cddis.2017.501

Zhang, Z., Song, M., Liu, X., Kang, S. S., Kwon, I.-S., Duong, D. M., et al. (2014). Cleavage of tau by asparagine endopeptidase mediates the neurofibrillary pathology in Alzheimer's disease. Nat. Med. 20, 1254-1262.

Zhou, Z., Xue, Q., Wan, Y., Yang, Y., Wang, J., and Hung, T. (2011). Lysosomeassociated membrane glycoprotein 3 is involved in influenza A virus replication in human lung epithelial (A549) cells. Virol. J. 8:384. doi: 10.1186/1743-422x8-384

Zientara-Rytter, K., and Subramani, S. (2019). The roles of ubiquitin-binding protein shuttles in the degradative fate of ubiquitinated proteins in the ubiquitin-proteasome system and autophagy. Cells 8:40. doi: 10.3390/ cells 8010040

Zomer, A., Maynard, C., Frederik, J. V., Kamermans, A., Schäfer, R., and Beerling, E. (2015). In Vivo imaging reveals extracellular vesicle-mediated phenocopying of metastatic behavior. Cell 161, 1046-1057. doi: 10.1016/j.cell.2015.04.042

Conflict of Interest: The authors declare that the research was conducted in the absence of any commercial or financial relationships that could be construed as a potential conflict of interest.

Copyright (c) 2021 Pedrioli and Paganetti. This is an open-access article distributed under the terms of the Creative Commons Attribution License (CC BY). The use, distribution or reproduction in other forums is permitted, provided the original author(s) and the copyright owner(s) are credited and that the original publication in this journal is cited, in accordance with accepted academic practice. No use, distribution or reproduction is permitted which does not comply with these terms. 